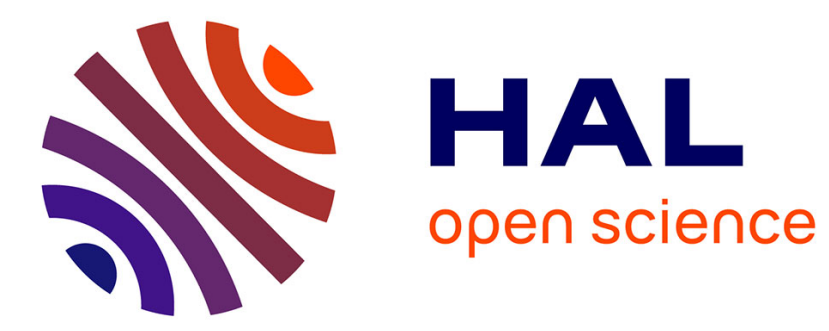

\title{
The brittle-to-viscous transition in polycrystalline quartz: An experimental study
}

Bettina Richter, Holger Stünitz, Renée Heilbronner

\section{To cite this version:}

Bettina Richter, Holger Stünitz, Renée Heilbronner. The brittle-to-viscous transition in polycrystalline quartz: An experimental study. Journal of Structural Geology, 2018, 114, pp.1-21. 10.1016/j.jsg.2018.06.005 . insu-01817648

\section{HAL Id: insu-01817648 \\ https://hal-insu.archives-ouvertes.fr/insu-01817648}

Submitted on 18 Jun 2018

HAL is a multi-disciplinary open access archive for the deposit and dissemination of scientific research documents, whether they are published or not. The documents may come from teaching and research institutions in France or abroad, or from public or private research centers.
L'archive ouverte pluridisciplinaire HAL, est destinée au dépôt et à la diffusion de documents scientifiques de niveau recherche, publiés ou non, émanant des établissements d'enseignement et de recherche français ou étrangers, des laboratoires publics ou privés. 


\section{Accepted Manuscript}

The brittle-to-viscous transition in polycrystalline quartz: An experimental study

Bettina Richter, Holger Stünitz, Renée Heilbronner

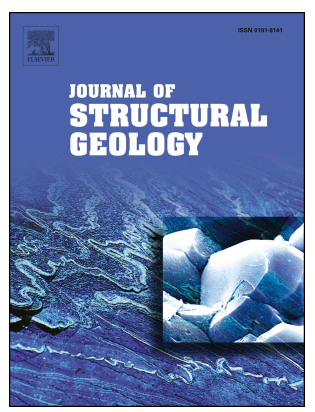

PII: S0191-8141(18)30275-X

DOI: $\quad$ 10.1016/j.jsg.2018.06.005

Reference: $\quad$ SG 3676

To appear in: Journal of Structural Geology

Received Date: 29 September 2017

Revised Date: 3 June 2018

Accepted Date: 3 June 2018

Please cite this article as: Richter, B., Stünitz, H., Heilbronner, René., The brittle-to-viscous transition in polycrystalline quartz: An experimental study, Journal of Structural Geology (2018), doi: 10.1016/ j.jsg.2018.06.005.

This is a PDF file of an unedited manuscript that has been accepted for publication. As a service to our customers we are providing this early version of the manuscript. The manuscript will undergo copyediting, typesetting, and review of the resulting proof before it is published in its final form. Please note that during the production process errors may be discovered which could affect the content, and all legal disclaimers that apply to the journal pertain. 
1 The brittle-to-viscous transition in polycrystalline quartz: an experimental study.

2 Bettina Richter ${ }^{1}$, Holger Stünitz ${ }^{2,3}$, Renée Heilbronner ${ }^{1,2}$

$3{ }^{1}$ Geological Institute, Basel University, Bernoullistrasse 32, 4055 Basel, Switzerland

$4 \quad{ }^{2}$ Department of Geology, Troms $\phi$ University, Dramsveien 201, 9037 Troms $\phi$, Norway

$5 \quad{ }^{3}$ Institut des Sciences de la Terre d'Orléans (ISTO), Université d'Orléans, 45071

6 Orléans, France

7 Corresponding author: Renée Heilbronner (renee.heilbronner@ unibas.ch)

10 Keywords (4-6):

11 brittle-to-viscous transition, grain size distribution, dislocation creep, quartz rheology,

12 stress exponent

14 Abstract (<250 words)

15 Shear experiments on quartz gouge were performed at elevated confining pressures

16 (predominantly $1.5 \mathrm{GPa}$ ) and temperatures $\left(500{ }^{\circ} \mathrm{C}-1000{ }^{\circ} \mathrm{C}\right)$ at shear strain rates of

$173.5 \cdot 10^{-6} \mathrm{~s}^{-1}$ to $2 \cdot 10^{-3} \mathrm{~s}^{-1}$ to study the brittle-to-viscous transition. An unsystematic

18 temperature dependence of strength at low temperatures changes towards a clear

19 temperature weakening dependence above $650{ }^{\circ} \mathrm{C}$. The transition from a pressure

20 strengthening to a pressure weakening relationship takes place continuously between

$21650{ }^{\circ} \mathrm{C}$ and $800{ }^{\circ} \mathrm{C}$. Strain rate stepping experiments reveal power-law breakdown at

22 low temperatures $\left(\sim 650{ }^{\circ} \mathrm{C}\right)$. Between $800{ }^{\circ} \mathrm{C}$ and $1000{ }^{\circ} \mathrm{C}$, a stress exponent of $n=$

$231.9 \pm 0.6$ and an activation energy of $\mathrm{Q}=170 \pm 72 \mathrm{~kJ} / \mathrm{mol}$ indicate a combination of

24 diffusion and dislocation creep. The Goetze criterion is confirmed as the upper stress

25 limit for viscous deformation mechanisms. Localised deformation in the form of 
26 semibrittle shear bands with Riedel geometry at low temperatures changes to

27 homogeneous deformation with a pervasive foliation accompanied by a continuous

28 texture evolution between $700{ }^{\circ} \mathrm{C}$ and $1000{ }^{\circ} \mathrm{C}$. Fracturing dominates at low

29 temperatures accompanied by increasing amounts of dissolution and precipitation in

30 fine-grained zones with increasing temperature. Above $650{ }^{\circ} \mathrm{C}$, dislocation and

31 diffusion creep are the dominating deformation processes, with dislocation creep

32 being favoured in larger grains while dissolution-precipitation is active in the fine-

33 grained fraction.

1. Introduction

The transition from fully brittle to fully viscous deformation in rocks (semi-

37 brittle field) occurs over a broad range of conditions in pressure, temperature, strain

38 rate, and $\mathrm{H}_{2} \mathrm{O}$-content with several changes in deformation mechanisms (e.g.,

39 Kohlstedt et al., 1995; Scholz, 2007; Hirth and Tullis, 1994). Viscous denotes

40 temperature- and strain-rate dependent deformation here. In the lithosphere, the

41 transition commonly takes place within the middle crust (continents) (e.g., Brace and

42 Kohlstedt, 1980; Handy, 1989; Sibson, 1989) but it may extend into the upper mantle

43 for some rocks, e.g., below the oceanic crust (e.g., Kohlstedt et al., 1995). The

44 transition region coincides with the greatest strength of rocks, and many large

45 earthquakes nucleate in this region (e.g., Sibson, 1989; Scholz, 2007).

46 Under conditions of brittle deformation (e.g., low temperatures, high strain

47 rates, typically shallow crustal levels), the strength of rocks primarily depends on

48 normal stress and pore pressure (Byerlee, 1978). Fracture strength and/or friction

49 control the rock deformation, leading to cataclastic processes (e.g., fracturing,

50 frictional sliding) with characteristic microstructures at greater strain. The intersection 
51 of Byerlee's law (Byerlee, 1978) with the Mohr-Coulomb fracture criterion marks the

52 onset of semi-brittle deformation in most lithologies (e.g., Kohlstedt et al., 1995). This

53 intersection is termed "brittle-ductile transition" and is temperature independent.

54 Viscous deformation at higher temperature, typically at deeper crustal levels, depends

55 on strain rates and temperatures, and is caused by diffusion and/or dislocation creep

56 involving recovery processes like dynamic recrystallisation (e.g., Poirier and

57 Guillope, 1979; Tullis and Yund, 1977; Yund and Tullis, 1991; Hirth and Tullis, 1994;

58 Tullis, 2002). The transition from semibrittle to viscous deformation is marked by the

59 brittle-to-viscous-transition (Kohlstedt et al., 1995) (BVT). The Goetze criterion has

60 been introduced as an ad hoc approximation by Kohlstedt et al. (1995) to delineate

61 this transition. It is formulated as $\Delta \sigma=$ Pc, i.e. the differential stress to drive viscous

62 flow is equal to the confining pressure.

63 In the transitional semi-brittle zone, stresses required to create new fractures

64 are lower than those for sliding on pre-existing faults (e.g., Byerlee, 1968; Kohlstedt et

65 al., 1995) causing pervasive fracturing and grain-size reduction (cataclasis).

66 Dislocations may be generated by cracking and healing processes (e.g., FitzGerald et

67 al., 1991; Tarantola et al., 2012; Trepmann and Stöckhert, 2013; Stünitz et al., 2017),

68 but whether these dislocations become important for crystal plasticity (dislocation

69 creep) depends on temperature and the efficiency of the recovery processes. At low

70 temperatures, tangling dislocations and high dislocation densities produce strain

71 hardening and greater stresses (e.g., Barber et al., 2010). Dominant crystal plasticity

72 is achieved at higher temperatures, where dislocation climb and recrystallisation are

73 rate controlling. For quartz, three types of dislocation creep regimes have been

74 identified dependent on the dominance of subgrain-rotation recrystallization or grain-

75 boundary migration (Hirth and Tullis, 1992). 
Grain size reduction by cracking may play an important role for the onset of

77 viscous deformation by increasing the surface area and decreasing the transport

78 distances, leading to accelerated mass-transfer processes (e.g., Pec et al., 2012;

79 Trepmann and Stöckhert, 2003; Menegon et al., 2008; Van Daalen et al., 1999). As a

80 result, deformation by diffusion creep may become the dominant mechanism should

81 such cracking occur (e.g., Paterson, 2013, p. 91-105, and references therein).

82 It emerges from this brief discussion that in the transition region of brittle-to-

83 viscous deformation, several processes are competing: cracking and frictional sliding,

84 crystal-plastic deformation, and diffusive mass transfer combined with friction-less

85 grain-boundary sliding. This study will try to address their relative importance for

86 deformation in quartz over a range of temperatures and confining pressures.

87 Quartz as one of the most abundant silicates in the Earth's crust is often used

88 to model and predict the mechanical behaviour of the upper lithosphere (e.g., Brace

89 and Kohlstedt, 1980). In addition, deformation mechanisms in quartz can be studied

90 independently of chemical effects because of its simple chemistry and very limited

91 compositional variation. Laboratory conditions (e.g., high strain rates: $10^{-3}-10^{-7} \mathrm{~s}^{-1}$,

92 high temperatures) have been extrapolated to natural conditions (e.g., low strain rates:

$9310^{-10}-10^{-14} \mathrm{~s}^{-1}$, low temperatures) via flow laws that are applicable for viscous

94 deformation (e.g., Jaoul et al., 1984; Kronenberg and Tullis, 1984; Paterson and

95 Luan, 1990; Luan and Paterson, 1992; Gleason and Tullis, 1995; Hirth et al., 2001;

96 Rutter and Brody, 2004a,b). However, few data exist to define the lower temperature

97 limit of the applicability of these flow laws. Futhermore, discrepancies exist for the

98 parameters of flow laws, so that the uncertainty for the users as to which data to use is

99 large, calling for a better characterisation of rheological properties of quartz.

100 We present a series of deformation experiments on quartz in a modified Griggs 
101 apparatus to study the rheological transition from brittle-to-viscous deformation

102 mechanisms at elevated pressures and temperatures. The goal is to determine the part

103 of the pressure-temperature-strain rate-range of the transition accessible in the

104 laboratory and to extrapolate it to natural conditions. Some rheological parameters

105 determined for quartz fault-rock material in this study can be used in flow laws for

106 quartz. The extrapolation of the conditions of the brittle-to-viscous transition to

107 natural fault zones will be discussed, together with some applications of the newly

108 determined parameters for the flow law.

2. Methods

\subsection{Experimental method}

113 The experiments were carried out on a crushed quartz crystal from a

114 hydrothermally grown single crystal from an Alpine cleft (Aar Massif, Switzerland).

115 Pieces of the crystal were repeatedly crushed and sieved to obtain a grain-size fraction

116 below $100 \mu \mathrm{m}$, used for what will be considered the standard experiments (referred to

117 as 'crushed'). One sample had a grain size range of $7-11 \mu \mathrm{m}$ (referred to as 'sieved').

118 The single crystal contained several fluid inclusions $(5-200 \mu \mathrm{m})($ Tarantola et al.,

119 2010). The quartz material itself was dry with a water content close to the detection

120 limit of FTIR measurements (Stünitz et al., 2017). Most inclusions, especially the

121 larger ones, cracked during the crushing procedure. The crushed material is used to

122 represent a fault gouge. However, during the time at experimental pressure and high

123 temperature, before deformation commenced, the crushed material was effectively hot

124 pressed to a dense coherent crystalline material better termed "cataclasite".

$125 \quad$ Insert Figure 1 here 
The crushed material $(0.1 \mathrm{~g})$ with $0.2 \mathrm{wt} \%$ water added was introduced

127 between alumina $\left(\mathrm{Al}_{2} \mathrm{O}_{3}\right)$ forcing blocks (diameter $6.35 \mathrm{~mm}$ ), cut at $45^{\circ}$ (to achieve

128 maximum shear stress), resulting in a layer of $\sim 1 \mathrm{~mm}$ thickness (Fig. 1). The assembly

129 was weld-sealed in a platinum jacket with a nickel foil insert. Sodium chloride was

130 used as confining medium in a Griggs-type solid-medium deformation apparatus (Fig.

131 1). The temperature was controlled by $\mathrm{S}$-type (Pt/Pt-Rh) thermocouples at $\mathrm{T}>800{ }^{\circ} \mathrm{C}$

132 and by $\mathrm{K}$-type $(\mathrm{Cr}-\mathrm{Al})$ thermocouples at $\mathrm{T} \leq 800{ }^{\circ} \mathrm{C}$. More details on the sample

133 assembly can be found in Pec (2014). Samples were pressurised to confining pressure

134 while the temperature was increased in $100{ }^{\circ} \mathrm{C}$ steps (at a rate of $20^{\circ} \mathrm{C}$ per minute) to

135 experimental conditions. The deformation experiments were started by applying a

136 directional compressive force on the sample, i.e., by moving the $\sigma_{1}$ piston (Richter et

137 al., 2016). The $\sigma_{1}$ piston had to push through a lead piece (so-called run-in) before it

138 touched the alumina forcing block on top of the sample. At this point sample

139 deformation started. When the motor was stopped, the temperature was decreased to

$140200{ }^{\circ} \mathrm{C}$ within $2-3$ minutes with cooling rates between $150{ }^{\circ} \mathrm{C}$ and $300{ }^{\circ} \mathrm{C}$ per minute

141 to quench the microstructure. Five experiments included a hydrostatic hot-pressing

142 stage (at $1000{ }^{\circ} \mathrm{C} ; 1.5-1.6 \mathrm{GPa}$ confining pressure), where the sample was left for 20

143 hours before decreasing the temperature $\left(2.5^{\circ} \mathrm{C}\right.$ per minute $)$ to deformation

144 conditions. These samples will be referred to as 'hot pressed'.

145 Two types of experiments were conducted. Experiments of type 1 were

146 conducted at constant displacement rates. The constant displacement rate of the $\sigma_{1}$

147 piston resulted in an approximately constant shear strain rate. Type 2 experiments are

148 strain-rate stepping experiments, where the displacement rate was decreased by about

149 one half or one order of magnitude after reaching peak strength. When steady state

150 was achieved for this reduced rate the displacement rate was decreased again. During 
151 the last step, the displacement rate was set again to the initial value.

152

155 the $\sigma_{1}$ piston, and the oil pressure of the confining pressure cylinder were recorded

156 with a frequency of $1 \mathrm{~Hz}$. These signals were converted to maximum principal stress

157 ( $\sigma_{1}$ in $\left.\mathrm{MPa}\right)$, minimum principal stress $\left(\sigma_{3}\right.$ in $\left.\mathrm{MPa}\right)$, and axial displacement $\left(d_{a}\right.$ in

$158 \mathrm{~mm})$. Data processing and determination of differential stress $(\Delta \sigma)$, shear stress $(\tau)$ and

159 shear strain $(\gamma)$ were performed according to Richter et al. (2016), including a

160 correction for confining pressure build-up and piston overlap. The shear strain $(\gamma)$ is

161 calculated as the sum of incremental shear strains between recorded data points. For

162 each data point, a reduced width of the shear zone is used by assuming a constant

163 linear thinning of the sample for a known initial average width from hot pressing

164 experiments and final deformed width measured in thin sections.

165 For the determination of the stress exponents and the activation energies, data

166 from the strain rate-stepping experiments and some of the constant shear strain-rate

167 experiments performed at the same deformation temperatures were used. The mean

168 steady-state differential stress and the mean shear strain-rate of each strain-rate step

169 and the differential stress at $\gamma \sim 3$ and the average shear strain rate of the constant

170 shear strain rate experiments were used. The stress corrections of Holyoke and

171 Kronenberg (2010) were not applied because they were not found to be appropriate

172 for the shear experiments in our apparatus (Richter et al., 2017).

173 The friction coefficient of the samples was calculated for the $45^{\circ}$ angle of the

174 forcing block pre-cut using a simple Mohr Coulomb construction: $\mu=\tau / \sigma_{n}$ (Fig. 1b).

175 During deformation, the normal stress on the sample $\left(\sigma_{n}\right)$ increases $\left(\sigma_{\mathrm{n}}\right.$ is calculated as 
176 2D mean stress). Steady-state shear stress at $\gamma=3$ was used to calculate the friction

177 coefficient for high strain experiments. For samples only loaded to peak-strength, the

178 maximum friction coefficient was calculated. In the strain rate-stepping experiments,

179 the stress value before decreasing the displacement rate was used for the first step, and

180 for the later strain rate steps the mean values at steady-state conditions were used.

2.3 Microstructure and texture analysis For the preparation of polished thin sections, the sample jackets were cut

184 parallel to the shear displacement direction and the samples were impregnated under

185 vacuum with epoxy before cutting. For all subsequent microstructural analyses, the

186 samples are viewed with a sinistral shear sense (shear zone boundary is horizontal).

187 All samples were analysed with light microscopy and scanning electron microscopy

188 (SEM; for imaging: a field emission Philips XL 30 ESEM, for electron backscatter

189 diffraction: a field emission Zeiss Merlin SEM with a Nordlys nano camera).

190 Electron backscatter diffraction (EBSD) was used to obtain quartz crystal

191 orientations. Polishing and lapping for EBSD analysis was carried out with colloidal

192 silica suspension Struers OP-U non dry for 3-6 minutes. Samples were coated with a

193 thin carbon layer to prevent charging under high vacuum conditions. Acceleration

194 voltages between $10 \mathrm{kV}$ and $15 \mathrm{kV}$ were used with step sizes of 0.1 to $0.2 \mu \mathrm{m}$. EBSD

195 data were measured with AZtec software and analysed with the MTEX toolbox

196 (Hielscher and Schaeben, 2008). Initial noise reduction was performed with

197 CHANNEL 5 software by removing isolated points and replacing non-indexed points

198 with the orientation of their neighbours (iteratively filled starting with eight similar

199 neighbours down to six or five similar neigbours).

200 Grain maps obtained with MTEX show individual grains separated by a 
201 misorientation angle of $10^{\circ}$. Dauphine twin boundaries (misorientation of $60 \pm 5^{\circ}$ )

202 were not considered grain boundaries. Grains had to contain at least five pixels to be

203 considered as grains. The $2 \mathrm{D}$ grain diameters $\left(\mathrm{d}_{\mathrm{equ}}=\right.$ diameter of area equivalent

204 circle) were used as input for the StripStar programme (Heilbronner and Barrett,

205 2014) to obtain the 3D diameters ( $D_{\text {equ }}=$ diameter of the volume equivalent spheres).

206 The volume weighted distributions of $\mathrm{D}_{\text {equ }}$ were fitted with a Gaussian Normal, the

207 modal value and the dispersion being given by the mean and the standard deviation.

208 For details on segmentation and grain size determination, see Heilbronner and Kilian

209 (2017).

210 The kernel average misorientation of a grain (gKAM) is calculated from noise

211 reduced EBSD data with a kernel of an order of 4 (see Kilian and Heilbronner, 2017).

212 The 'mis2mean' value of each point of a grain is determined with MTEX. Averaging

213 the 'mis2mean' value of a single grain yields the grain orientation spread (GOS). The

214 GOS is normalised for the long axis $\left(\mathrm{GOS}_{\mathrm{la}}\right)$ to account for the grain-size dependence,

215 which is especially pronounced for highly elongated grains. Both, $\mathrm{GOS}_{\mathrm{la}}$ and gKAM,

216 indicate the misorientation density of a grain and are therefore considered a measure

217 for intragranular deformation (for derivations of GOS, see Cross et al., 2017).

218 Using smoothed grain boundaries, the PARIS factor, a measure for grain

219 boundary lobateness (Panozzo and Hürlimann, 1983) is used. It is defined by the

220 difference between the length of the convex hull of a grain and that of the real

221 perimeter.

3. Mechanical results

27 constant shear strain-rate experiments between $500{ }^{\circ} \mathrm{C}$ and $1000{ }^{\circ} \mathrm{C}$ (Table

225 1) and five strain rate-stepping experiments at shear strain rates between $\sim 2.5 \times 10^{-6} \mathrm{~s}^{-}$ 
$226{ }^{1}$ and $\sim 2.5 \times 10^{-3} \mathrm{~s}^{-1}$ for $\sim 650{ }^{\circ} \mathrm{C}, 800{ }^{\circ} \mathrm{C}, 900{ }^{\circ} \mathrm{C}$ and $1000{ }^{\circ} \mathrm{C}$ (Table 2) were

227 conducted.

Insert Table 1 and 2 here

\subsection{Temperature dependence}

231 Above temperatures of $\sim 650{ }^{\circ} \mathrm{C}$, samples clearly weaken systematically with

232 increasing temperature, whereas at $650{ }^{\circ} \mathrm{C}$ and below, the strength-temperature-

233 relationship is weak or unsystematic (Fig. 2a). Samples deformed at temperatures

234 below $700{ }^{\circ} \mathrm{C}$ show steady-state behaviour or slight strain hardening. At $700{ }^{\circ} \mathrm{C}$ or

235 higher, the samples deform below the Goetze criterion $\left(\Delta \sigma=\mathrm{P}_{\mathrm{c}}\right)$ and show steady-

236 state or minor strain weakening at high strain. The difference in strength between 650

$237{ }^{\circ} \mathrm{C}$ and $700{ }^{\circ} \mathrm{C}$ is very large $(\sim 1300 \mathrm{MPa})$. At low temperatures, no significant stress

238 drop or strain weakening occur after yield strength, except for $450 \mathrm{br}$ and $481 \mathrm{br}$ (see

239 Table 1). These samples show a stress drop as a result of slip along the forcing block.

240 In addition, the alumina forcing blocks started to deform because of the high stresses

241 (e.g., 415br).

242 The slopes of the loading curves up to temperatures of $650{ }^{\circ} \mathrm{C}$ are almost

243 identical up to a differential stress of $\sim 1 \mathrm{GPa}$. At temperatures above $650{ }^{\circ} \mathrm{C}$ the slope

244 decreases with decreasing strength and shear strain rate (Figs. 2, 3 and 4).

$245 \quad$ Insert Figure 2 here

3.2 Pressure dependence

248 At $650{ }^{\circ} \mathrm{C}$, the sample strength increases with increasing confining pressure,

249 whereas at higher temperatures $\left(700^{\circ} \mathrm{C}\right.$ and $800{ }^{\circ} \mathrm{C}$; Fig. 3) strength decreases with

250 increasing confining pressure. At $800^{\circ} \mathrm{C}$, a pressure dependence is not obvious 
251 between 1.0 and $1.5 \mathrm{GPa}$, but between 0.5 and $1.0 \mathrm{GPa}$, the weakening with

252 increasing confining pressure is very clear (Fig. 3).

\section{Insert Figure 3 here}

When hot pressed at $1000{ }^{\circ} \mathrm{C}$ for 20 hours prior to deformation, samples

258 2c). The difference in flow stress is at least $500 \mathrm{MPa}$ at $600{ }^{\circ} \mathrm{C}$ at $\gamma \sim 3$ (the forcing

259 blocks start to deform in the hot-pressed sample at such high stresses). At $700{ }^{\circ} \mathrm{C}$, the

260 hot-pressed sample is about $900 \mathrm{MPa}$ stronger and shows strain hardening, whereas

261 the non-hot pressed sample weakens. At $800{ }^{\circ} \mathrm{C}$, the difference is $\sim 200 \mathrm{MPa}$ and both

262 samples show strain weakening.

263 One sample with a small initial grain-size fraction $(7-11 \mu \mathrm{m})$ is deformed at

$2641.5 \mathrm{GPa}, 800{ }^{\circ} \mathrm{C}$ and $2.5 \cdot 10^{-5} \mathrm{~s}^{-1}$ (Fig. 2c, 445br). It is weaker than the experiments

265 with a larger initial grain-size fraction $(<100 \mu \mathrm{m})$ performed at the same strain rate

266 and temperature conditions. At $\gamma \sim 3$, the differential stress of $445 \mathrm{br}$ is less than half as

267 high as of 388br (difference $\sim 500 \mathrm{MPa}$ ). Steady-state conditions exist between a

268 shear strain of $\sim 0.5$ to 2.5 , after that the sample hardens by $\sim 100 \mathrm{MPa}$ until the end of

269 the experiment.

Strain rate has a pronounced effect on sample strength at temperatures above

$273600{ }^{\circ} \mathrm{C}$. At $650{ }^{\circ} \mathrm{C}$ and $800{ }^{\circ} \mathrm{C}$, increasing the strain rate by one order of magnitude

274 shifts the flow stress from below to above the Goetze criterion (Fig. 2b). At $900{ }^{\circ} \mathrm{C}$

275 the same shift is achieved by increasing the strain rate by two orders of magnitude. 
Strain rate-stepping experiments in combination with constant displacement

277 experiments at different rates show distinct strain rate dependence for all higher

278 temperature experiments, except at $650{ }^{\circ} \mathrm{C}$, where the rate dependence is only

279 observed at very low strain rates $\left(\sim 10^{-6} \mathrm{~s}^{-1}\right.$; Fig. 4). The fastest strain rate causes the

280 highest stresses, and lower stresses with increasing temperature and lower strain rate

281 occur at all strain rates (Fig. 4). The strain-rate-stepping tests are plotted together with

282 constant strain-rate tests to check the reproducibility of the results. At $900{ }^{\circ} \mathrm{C}$ and

$2831000^{\circ} \mathrm{C}$, the last step has slightly higher shear strain-rates than the first step (because

284 of the thinning of the shear zone), and therefore, the differential stress is slightly

285 higher. The experiment at $900{ }^{\circ} \mathrm{C}$ shows abrupt strain hardening at the end of the last

286 strain rate step. This behaviour is a consequence of the sample geometry where the

287 lower forcing block collided with the upper alumina piston. At $800{ }^{\circ} \mathrm{C}$, the experiment

288 failed at the slowest strain rate step.

\section{Insert Figure 4 here}

290 One strain-rate-stepping experiment included a hot-pressing stage prior to

291 deformation (480br). The initial sample strength is similar to that of the hot-pressed

292 constant-displacement experiment (419br, Fig. 4). At lower strain rates, the stresses of

293 the hot-pressed sample are similar the sample 388br without hot pressing. At the end

294 of the experiment, the strain-stepping sample (480br) is $200 \mathrm{MPa}$ weaker than the

295 constant rate sample (419br).

4. Microstructural observations

The brittle and the viscous microstructures are described in terms of being

299 discrete Riedel surfaces without discernible shear displacement and a synthetic low-

300 angle orientation (R) or an antithetic high-angle orientation ( $\left.\mathrm{R}^{\prime}\right)$ with respect to the 
301 shear plane are termed "Riedel surfaces". When such features have a discernible

302 width, they are termed "shear bands" (SB, not distinguishing $\mathrm{C}$ or $\mathrm{C}^{\prime}$ orientations in

303 the sense of Berthé et al. (1979)). Riedel surfaces and shear bands may occur in the

304 same sample. Elongated quartz grains or grain aggregates typically develop a shape

305 preferred orientation, which is termed "foliation" (F) here.

\subsection{Starting material}

From analyses with a laser diffraction particle size analyzer, we know that the

309 crushed quartz powder initially has a fractal size distribution with a fractal dimension

310 of 2.4 in the size range up to $100 \mu \mathrm{m}$. During the run-in of the $\sigma_{1}$-piston, before the

311 piston touches the forcing block, the samples are exposed to varying periods (up to 25

312 hours) of hydrostatic heat treatment. During this time, the same kind of grain growth

313 takes place as in the healing faults described by Keulen et al. (2008), so that the grain-

314 size fraction $<1 \mu \mathrm{m}$ disappears (Fig. 5). Grain growth creates a normal distribution of

315 grains at the lower size end of the fractal distribution.

316 A few samples were additionally hot pressed after reaching experimental

317 conditions $\left(20 \mathrm{~h}\right.$ at $\left.1000^{\circ} \mathrm{C}\right)$. After $25 \mathrm{~h}$ and $800^{\circ} \mathrm{C}$, the $3 \mathrm{D}$ mode of the grain size

318 fraction $<30 \mu \mathrm{m}$ is $\sim 9.1 \mu \mathrm{m}$, and after $20 \mathrm{~h}$ at $1000{ }^{\circ} \mathrm{C}$, it is $\sim 12.8 \mu \mathrm{m}$ (Table 3). The

319 initial gouge material is now fully compacted and fully cohesive. For the higher

320 temperature samples $\left(700{ }^{\circ} \mathrm{C}\right.$ to $1000{ }^{\circ} \mathrm{C}$ ), porosity is $<1 \%$, whereas for lower

321 temperature samples $\left(500\right.$ to $600^{\circ} \mathrm{C}$ ) porosity is up to $\sim 10 \%$ (values obtained from

322 image analysis) due to a lack of grain growth.

$323 \quad$ Insert Figure 5 here

$324 \quad$ Insert Table 3 here 
4.2 Deformation microstructures

328 surface geometry with synthetic R and rare antithetic R' surfaces (Fig. 6; samples

$329450 \mathrm{br}, 479 \mathrm{br}, 415 \mathrm{br}, 435 \mathrm{br})$. The R surfaces form at an angle of $20-30^{\circ}$ to the

330 direction of the applied load ( $\sigma_{1}$ - direction) and have a predominantly brittle

331 appearance at $500^{\circ} \mathrm{C}$. The R surfaces are not connected and never transect the whole

332 sample. These observations, in conjunction with the mechanical data, indicate that

333 these R surfaces do not fully control the sample strength. Most original clasts are still

334 visible but have rounded edges and corners. Undulatory extinction and discrete

335 surfaces with small misorientation and with a high angle towards the shear zone

336 boundary exist in several clasts at $650^{\circ} \mathrm{C}$ (Fig. 6; sample $435 \mathrm{br}$ ). Tails at clasts are

337 partly developed without resolvable small particles at the light or scanning electron

338 microscope scale at $650^{\circ} \mathrm{C}$. Deformation lamellae start to develop in clasts at $600{ }^{\circ} \mathrm{C}$.

339 Shear bands are developed at $650{ }^{\circ} \mathrm{C}$ in addition to the $\mathrm{R}$ surfaces. At $600{ }^{\circ} \mathrm{C}$, zones

340 with small, equi-axed grains evolve in $\mathrm{R}$ surface orientation. These zones become

341 more pronounced at higher temperatures, defining shear bands (Fig. 6; samples 479br,

342 435br, 493br, 419br).

$343 \quad$ Insert Figure 6 here

344 At higher temperatures $\left(\mathrm{T} \geq 700^{\circ} \mathrm{C}\right)$, viscous processes dominate the

345 microstructure (Fig. 6; samples 383br, 388br, 412br, 493br, 419br). At $700{ }^{\circ} \mathrm{C}$ and

$346800{ }^{\circ} \mathrm{C}$, a shear band and foliation fabric is developed (Figs. 6, 7; samples 383br,

347 388br, 412br, 493br, 419br, 452br, 447br, 448br, 499br), and Riedel surfaces are

348 absent. Elongated tails of recrystallized grains develop at rounded clasts. With

349 increasing shear strain and higher temperature, the shear band and foliation fabric

350 evolves into a single penetrative foliation of elongated clasts and recrystallised grains. 
351 Large clasts show more penetrative recrystallisation with increasing temperature of

352 deformation and with increasing strain. At $\gamma \sim 5$ about $10 \%$ clasts remain at $700{ }^{\circ} \mathrm{C}$

353 and $5 \%$ clasts can be distinguished at $800{ }^{\circ} \mathrm{C}$ (Fig. 6; samples 383br, 493br, 388br).

354 Rounded clasts are predominant at $700{ }^{\circ} \mathrm{C}$. At $800{ }^{\circ} \mathrm{C}$, highly elongated aggregates of

355 recrystallised grains dominate. Deformation lamellae are pronounced in clasts at 700

$356{ }^{\circ} \mathrm{C}$ and $800{ }^{\circ} \mathrm{C}$, but rare at $900{ }^{\circ} \mathrm{C}$. At $900{ }^{\circ} \mathrm{C}$ and $1000{ }^{\circ} \mathrm{C}$, the elongated aggregates

357 of recrystallised grains give way to a more homogeneous groundmass of recrystallised

358 grains with some clasts preserved in the recrystallised matrix (Fig. 6; samples 412br, $359337 \mathrm{br})$.

360 In samples with hot pressing $\left(20 \mathrm{~h}\right.$ at $\left.1000^{\circ} \mathrm{C}\right)$, pre-existing cracks are anneal

361 and barely visible. Subsequent deformation at $600{ }^{\circ} \mathrm{C}$ does not produce an obvious

362 brittle deformation fabric of the sample (Fig. 6; sample 415br). No Riedel surfaces

363 develop and only minor grain-boundary alignment occurs. At $700{ }^{\circ} \mathrm{C}$ and high strains,

364 a shear band and foliation fabric is present with several remaining rounded clasts that

365 develop tails (Fig. 6; samples 493br). At a given shear strain, the foliation angle with

366 the shear zone boundary is clearly larger than in samples without hot pressing and the

367 microstructure appears less deformed. At $800{ }^{\circ} \mathrm{C}$, a pervasive foliation dominates the

368 fabric, again with a slightly larger angle after similar shear strain than in the hot

369 pressed sample (Fig. 6; sample 483br). More or less elongated clasts are present

370 compared to the sample without hot pressing.

4.3 Effect of strain rate on microstructure

373 Three constant shear strain-rate experiments were conducted at shear strain

374 rates different from $\sim 2.5 \cdot 10^{-5} \mathrm{~s}^{-1}$ (Fig. 2b). At $650{ }^{\circ} \mathrm{C}$ and a shear strain rate of

$3750.35 \cdot 10^{-5} \mathrm{~s}^{-1}$ several grains show more brittle deformation, and less rounded grain 
376 shapes at low shear strain $(\gamma=1.1$; Fig. 7; sample 500br). Shear bands are absent and

377 the fabric resembles samples deformed at lower temperatures at $2.5 \times 10^{-5} \mathrm{~s}^{-1}$ (Fig. 6;

378 sample $479 \mathrm{br})$. At $800^{\circ} \mathrm{C}$ and $900{ }^{\circ} \mathrm{C}$, faster shear strain rates $\left(27 \cdot 10^{-5} \mathrm{~s}^{-1}\right.$ and $189 \cdot 10^{-}$

$3795^{5} \mathrm{~s}^{-1}$, respectively) cause a more heterogeneous deformation, shear bands, and samples

380 resemble those deformed at $\sim 100$ to $200{ }^{\circ} \mathrm{C}$ lower temperatures at strain rats of $2.5 \mathrm{x}$

$38110^{-5} \mathrm{~s}^{-1}$ (Fig. 7; samples 447br, 499br).

$382 \quad$ Insert Figure 7 here

383

4.4 Effect of confining pressure on microstructure

Samples deformed at $1.0 \mathrm{GPa}$ confining pressure and $650^{\circ} \mathrm{C}$ show Riedel

386 surfaces and less commonly shear bands, very similar to samples deformed at $1.5 \mathrm{GPa}$

387 confining pressure (Figs. 6, 7; samples 494, 435br). Clast shapes are less rounded than

388 at $1.5 \mathrm{GPa}$ confining pressure (cf. Figs. 6 and 7, shear strain is higher in Fig. 7;

389 samples $494 \mathrm{br}, 435 \mathrm{br})$. At $700{ }^{\circ} \mathrm{C}, 1.0 \mathrm{GPa}$, the samples are characterised by a larger

390 number of shear bands and less homogeneous deformation than at $1.5 \mathrm{GPa}$ (cf. Figs. 6

391 and 7; samples 494br, 435br), whereas at $800{ }^{\circ} \mathrm{C}, 1.0 \mathrm{GPa}$, more clasts survive and the

392 recrystallisation is less complete than at $1.5 \mathrm{GPa}$ (cf. Figs. 6 and 7; samples $448 \mathrm{br}$, 393 388br).

394 At $0.5 \mathrm{GPa}$ confining pressure and $800{ }^{\circ} \mathrm{C}$, deformation is localised in long 395 synthetic R surfaces accompanied by several transgranular fractures (Fig. 8; sample

396 386br). Most of the displacement is accumulated along the $\mathrm{R}$ surfaces, where the

397 gouge material is highly pulverised (submicron-scale) (Fig. 8b). Large clasts are 398 slightly rounded at the edges (Fig. 8a) and microstructures resemble those of the $399650^{\circ} \mathrm{C}, 1.5 \mathrm{GPa}$ sample (cf. Fig. 6; sample 435br). In the series of 0.5, 1.0, and 1.5

400 GPa samples, more brittle deformation microstructures clearly develop with 
401 decreasing confining pressure, particularly toward the lower pressure end. Insert Figure 8 here

403

404

\subsection{Grain size}

405

At conditions of $1.5 \mathrm{GPa}$ confining pressure and shear strain rates of $\sim 3 \cdot 10^{-5} \mathrm{~s}$

$406{ }^{1}$, the $3 \mathrm{D}$ mode of recrystallized grain size increases from $2.1 \mu \mathrm{m}$ at $700{ }^{\circ} \mathrm{C}$ to $>15 \mu \mathrm{m}$

407 at $1000{ }^{\circ} \mathrm{C}$ (Fig. 9a, Table 3). The sample that was prepared with a grain-size fraction

408 of 7-10 $\mu \mathrm{m}$, yields a slightly larger grain size of $4.4 \mu \mathrm{m}$ compared to the standard

409 sample that yields $4.1 \mu \mathrm{m}$ at the same temperature $\left(800^{\circ}\right)$ (Fig. $\left.9 \mathrm{~b}\right)$. At $1.0 \mathrm{GPa}$

410 confining pressure, the recrystallised grain size is slightly smaller than at $1.5 \mathrm{GPa}(1.5$

411 versus $2.1 \mu \mathrm{m}$ at $700{ }^{\circ} \mathrm{C}$, and 3.3 versus $4.1 \mu \mathrm{m}$ at $800^{\circ} \mathrm{C}$ ). At $0.5 \mathrm{GPa}$ and $800{ }^{\circ} \mathrm{C}$, no

412 recrystallization occurs. Shear strain rates faster than the standard value of $3 \cdot 10^{-5} \mathrm{~s}^{-1}$

413 cause smaller recrystallised grain sizes. At $800{ }^{\circ} \mathrm{C}$ and 10 times faster, the $3 \mathrm{D}$ mode is

$4142.0 \mu \mathrm{m}$ versus $4.1 \mu \mathrm{m}$, at $900{ }^{\circ} \mathrm{C}$ and 100 times faster, it is $1.5 \mu \mathrm{m}$ versus $6.1 \mu \mathrm{m}$

415 (Table 3).

$416 \quad$ Insert Figure 9 here

417 An initial hot-pressing stage causes growth of the small grains (Fig. 5, Table 3)

418 and the resulting grain sizes at the onset of deformation are larger. After deformation,

419 the recrystallized grain size of these samples is similar to that of samples without hot

420 pressing $\left(1.6 \mu \mathrm{m}\right.$ compared to $2.1 \mu \mathrm{m}$ at $700{ }^{\circ} \mathrm{C}, 4.8 \mu \mathrm{m}$ compared to $4.1 \mu \mathrm{m}$ at 800

$421{ }^{\circ}$ C; cf. Fig. 9b, Table 3).

422

\subsection{Texture}

424 The values of GOS and gKAM, indicators of intragranular deformation,

425 decrease with increasing temperature between $700{ }^{\circ} \mathrm{C}$ and $1000{ }^{\circ} \mathrm{C}$ (Fig. 10) with hot 
426 pressed samples showing similar values to samples without hot pressing. For

427 individual grains, neither PARIS factors, indicating high lobateness, nor grain size

428 correlate with GOS and gKAM values.

$429 \quad$ Insert Figure 10 here

430 Above $650{ }^{\circ} \mathrm{C}$, the recrystallised matrix dominates the CPO for standard

431 confining pressure $(1.5 \mathrm{GPa})$ and standard shear strain rates $\left(\sim 2.5 \cdot 10^{-5} \mathrm{~s}^{-1}\right)$. Separate

432 pole figures are calculated for smaller and larger fractions of recrystallized grains

433 (Fig. 11). The delimiting size between small and large grains is derived from the 3D

434 mode of the size distribution of recrystallized grains $(<25 \mu \mathrm{m}$; Fig. 11). Pole figures

435 are calculated for grains with 2D diameters (= area equivalent diameters) larger or

436 smaller than the delimiting 3D diameter, i.e., pole figures for grains larger than the 3D

437 mode and pole figures for grains predominantly smaller than the $3 \mathrm{D}$ mode. For the

438 larger grain size fraction, the CPO is always considerably stronger. The CPO

439 progressively evolves between $700{ }^{\circ} \mathrm{C}$ and $1000{ }^{\circ} \mathrm{C}$. At $700{ }^{\circ} \mathrm{C}$ and $800{ }^{\circ} \mathrm{C}$, there is

440 one peripheral maximum of the $c$-axes slightly rotated with the sense of shear. At 900

$441{ }^{\circ} \mathrm{C}$, a peripheral and a central $c$-axis maximum both are established. Towards $1000{ }^{\circ} \mathrm{C}$

442 the CPO evolves to a single central $c$-axes maximum.

443 The pole figures of the fine-grained fraction shows a different development

444 with increasing temperature. At $700^{\circ} \mathrm{C}$, the $\mathrm{CPO}$ is more diffuse and the peripheral $c$ -

445 axis maximum is less pronounced compared to that of the larger grain size. The

446 orientation of the maximum is similar to the maximum of the larger grains. At $800{ }^{\circ} \mathrm{C}$,

447 the smaller grains $(<4 \mu \mathrm{m})$ again show a more diffuse $\mathrm{CPO}$, but the $c$-axis maximum

448 is rotated by $20^{\circ}$ with the sense of shear with respect to that of the larger grains. At

$449900{ }^{\circ} \mathrm{C}$, the peripheral c-axes are more dispersed and the c-axis maximum is rotated

450 by $10^{\circ}$ with the sense of shear compared to that of the larger grains. The central 
451 maximum of $c$-axes is less pronounced than that of the larger grains. The central c-

452 axis maximum at $1000^{\circ} \mathrm{C}$ is present in fine grains as well as in larger grains. A

453 rotation with the sense of shear cannot be identified.

\section{Insert Figure 11 here}

5. Discussion

Our series of experiments employs crushed material of natural quartz. This

458 approach simulates a cataclasite produced by brittle deformation in nature such as

459 seismic or aseismic movement along a fault. Such a cataclastic rock deforms

460 dominantly by frictional mechanisms at low temperatures, high strain rates and low

461 confining pressures, and by fully viscous mechanisms at higher temperatures, lower

462 strain rates and higher confining pressures. The differences in the mechanical data and

463 microstructures demonstrate that the starting material used here is adequate to study

464 the brittle-to-viscous transition (BVT) as a function of pressure, temperature and

465 strain rate in polycrystalline quartz rocks. Another aspect that may be studied by using

466 such a material is how deformation mechanisms change as a function of deformation

467 history, i.e. from a brittle precursor material to a subsequently viscously deformed

468 material. Such a transition may occur, e.g., as a transition from seismic to postseismic 469 creep.

5.1 Mechanical parameters of the brittle-to-viscous transition

The BVT can be defined on the basis of different parameters: mechanical data

473 with respect to the Goetze criterion $\left(\Delta \sigma \approx P_{c}\right)$; pressure dependence of differential

474 stress; friction coefficients and stress exponents, and microstructural transition from

475 dominantly brittle to viscous deformation structures. 
The greatest difference in differential stress at a strain rate of $\sim 10^{-5} \mathrm{~s}^{-1}$ is

477 observed between the $600 / 650{ }^{\circ} \mathrm{C}$ and $700{ }^{\circ} \mathrm{C}$ samples (Fig. 2a) where the strengths

478 lie above and below the Goetze criterion that marks the transition from brittle $(\Delta \sigma>$

$\left.479 P_{c}\right)$ to viscous $\left(\Delta \sigma<P_{c}\right)$ deformation ("plastic" in Kohlstedt et al., 1995). This

480 observation places the BVT between $650{ }^{\circ} \mathrm{C}$ and $700{ }^{\circ} \mathrm{C}$ for a strain rate of $\sim 10^{-5} \mathrm{~s}^{-1}$ in

481 terms of the Goetze criterion.

$482 \quad$ For experiments by others at the same axial strain rates as our shear strain rates

483 (Hirth and Tullis, 1994), the strength of quartzite samples at $700{ }^{\circ} \mathrm{C}$ and $850{ }^{\circ} \mathrm{C}$ (at $P_{c}$

$484=1.2 \mathrm{GPa}$ ) shows substantial scatter, but similar average values as our samples. The

485 deformation processes in that study were identified as semi-brittle flow $\left(700{ }^{\circ} \mathrm{C}\right)$ and

486 dislocation creep $\left(850^{\circ} \mathrm{C}\right)$. The similar sample strengths of the intact rock and our

487 gouge material indicate that at higher temperatures the cataclasite is fully compacted

488 and behaves like a normal polycrystalline material. We attribute the temperature

489 differences for the BVT between our samples and those of Hirth and Tullis (1994) to

490 differences in the amount of total strain attained and that samples in shear are weaker

491 than in axial compression, so that localisation in coaxially deformed samples occurs in

492 narrower zones than in our shear zones, causing greater strain rates.

493 The BVT coincides with another mechanical observation in the samples: At

494 stresses below the Goetze criterion, the slope of the loading part of the stress strain

495 curves decreases systematically with decreasing flow stress (Figs. 2, 3 and 4). The

496 loading curve in the Griggs apparatus is not purely elastic at higher temperatures. The

497 systematically decreasing slope at higher temperatures is the result of increasing

498 viscous deformation processes in the samples during loading. In experiments

499 deformed above the Goetze criterion, the slope is similar for all samples, indicating no

500 substantial viscous deformation processes during loading. 
Higher confining pressures cause greater sample strength for frictional sliding

502 (Byerlee, 1978) and cracking (Paterson and Wong, 2005 and references within),

503 whereas the viscous creep strength of wet quartz decreases with increasing confining

504 pressure (Tullis et al., 1979; Kronenberg and Tullis, 1984). The observed

505 strengthening of samples with increasing pressure at low temperatures $\left(650{ }^{\circ} \mathrm{C}\right.$, Fig. 3)

506 is consistent with frictional or brittle behaviour (cf. Hirth and Tullis, 1994). The

507 lowering of flow-stress with increasing pressure observed at $T>650{ }^{\circ} \mathrm{C}$ (Fig. 3)

508 indicates the onset of viscous deformation. At a first glance, the difference in flow

509 stress between samples deformed at 1.0 and $1.5 \mathrm{GPa} \mathrm{P}_{\mathrm{c}}(453 \mathrm{br}$ and $437 \mathrm{br})$ does not

510 appear significant (Fig. 3), but when seen with respect to the Goetze criterion, the

511 difference is well defined: The sample at $1.5 \mathrm{GPa}$ (437br) barely reaches the Goetze

512 criterion, whereas the sample at $1.0 \mathrm{GPa}$ (453br) is clearly above it. The difference in

513 flow stress is clearly established at low $\mathrm{P}_{\mathrm{c}}$ between $0.5 \mathrm{GPa}$ and $1.0 \mathrm{GPa}$ (Fig. 3). A

514 very similar trend was observed in novaculite by Kronenberg and Tullis (1984): a

515 smaller stress dependence at $P_{c} \geq 1.0 \mathrm{GPa}$ and a distinct pressure dependence at lower

516 confining pressures. The decreasing peak stress with increasing pressure is related to

517 increased water fugacity and its enhancing effect on crystal plasticity (Tullis et al.,

518 1979; Kronenberg and Tullis, 1984; Paterson and Luan, 1990; Kohlstedt et al., 1995).

519 The pressure dependence delineates the BVT also in the range of $650{ }^{\circ} \mathrm{C}$ to $700{ }^{\circ} \mathrm{C}$ for $520 \sim 10^{-5} \mathrm{~s}^{-1}$.

5.2 Coefficient of friction

To delineate the BVT better, mechanical properties such as friction coefficient

524 and stress exponent can be used. Frictional deformation should be rather temperature

525 insensitive up to 440 to $500{ }^{\circ} \mathrm{C}$ (Paterson and Wong, 2005, p. 172), whereas viscous 
526 deformation is by definition temperature dependent. Viscous flow laws imply a strong

527 positive stress dependence for the strain rate (Orowan, 1940; Kohlstedt and Hansen,

528 2015), whereas in frictional deformation the strain rate at slow sliding rates (as

529 employed in this study) are assumed to be weakly dependent or strain-rate

530 independent as a first approximation (Byerlee, 1978; Kohlstedt et al., 1995; Paterson

531 and Wong, 2005, p. 178, and references therein). To better use the mechanical data for

532 defining the BVT, we determined the friction coefficients and stress exponents for

533 many of our experiments, even if these mechanical properties are outside the range of

534 conditions for which brittle deformation would be expected.

535 At $1.5 \mathrm{GPa}$ and below $700{ }^{\circ} \mathrm{C}$, the friction coefficient $(\mu \sim 0.45$; Fig. 12) is

536 somewhat less than normal rock friction values (0.6; Byerlee, 1978). The temperature

537 dependence is very small up to $650{ }^{\circ} \mathrm{C}$. From $700{ }^{\circ} \mathrm{C}$ to $1000{ }^{\circ} \mathrm{C}$, the friction

538 coefficient shows a systematic temperature dependence. At 1.5 GPa confining

539 pressure and a strain rate of $2.5 \cdot 10^{-5} \mathrm{~s}^{-1}$, the friction coefficient $\mu \sim 0.3$ to 0.05 , at a

540 strain rate of $2.5 \cdot 10^{-4} \mathrm{~s}^{-1}, \mu \sim 0.35$ to 0.16 . At strain rates of $\sim 10^{-6} \mathrm{~s}^{-1}$, the friction

541 coefficients become very small $(\mu<0.02)$. Low confining pressures cause greater

542 friction coefficients between $650{ }^{\circ} \mathrm{C}$ and $800{ }^{\circ} \mathrm{C}$ (Fig. 12b): At $0.5 \mathrm{GPa}$ and $800{ }^{\circ} \mathrm{C}$,

543 the greatest friction coefficient occurs $(\mu=0.53)$, which is twice the value at $1.0 \mathrm{GPa}$.

544 A distinct jump in the values occurs for the friction coefficient between $650{ }^{\circ} \mathrm{C}$ and

$545700{ }^{\circ} \mathrm{C}$ for a strain rate of $2.5 \times 10^{-5} \mathrm{~s}^{-1}$, coinciding with the Goetze criterion (Fig. 12).

$546 \quad$ Insert Figure 12 here

547 Frictional deformation in quartz and granite, in general, is only weakly

548 temperature-dependent below $350-400{ }^{\circ} \mathrm{C}$ (Blanpied et al., 1995; Chester and Higgs,

549 1992), so that the smaller friction coefficients and the strong temperature dependence

550 at $\mathrm{T}>650{ }^{\circ} \mathrm{C}$ also indicate a change in deformation mechanism to viscous behaviour. 
552 (Figs. 2b, 4, 12a) is present down to temperatures as low as $650{ }^{\circ} \mathrm{C}$ (Fig. 4). This

553 behaviour emphasises the contribution of viscous deformation processes, and thus a

554 semi-brittle character at these low temperatures. It is remarkable that in one sample

555 (500br) at temperatures of $650^{\circ} \mathrm{C}$, the flow stress can be below the Goetze criterion.

556 However, in that sample, steady state was not achieved because at the low strain rate

557 of $\sim 10^{-6} \mathrm{~s}^{-1}$ only a small total strain was attained (Figs. $2 \mathrm{~b}$ and 4 ). Strain rates of $\sim 10^{-4}$

$558 \mathrm{~s}^{-1}$ are required to achieve sample strengths above the Goetze criterion and realistic

559 friction coefficients at $T=800{ }^{\circ} \mathrm{C}$, whereas a strain rate of $\sim 10^{-3} \mathrm{~s}^{-1}$ is required at $T=$

$560900{ }^{\circ} \mathrm{C}$ (Figs. 2b, 12a). These results can be used to extrapolate the BVT to lesser

561 strain rates (see below).

\subsection{Stress exponent and activation energy}

Based on a power-law creep relationship, the stress and strain rate data can be

565 used to derive a stress exponent and an activation energy (Fig. 13):

$$
\gamma=A \cdot \Delta \sigma^{n} \cdot \exp ^{-\frac{Q}{R \cdot T}}
$$

568 constant, $\Delta \sigma[\mathrm{MPa}]$ is the differential stress, $n$ is the stress exponent, $Q[\mathrm{~J} / \mathrm{mol}]$ is the

569 activation energy, $R\left[\mathrm{~J} \cdot \mathrm{mol}^{-1} \cdot \mathrm{K}^{-1}\right]$ is the ideal gas constant and $T[\mathrm{~K}]$ is the

570 temperature. At low temperatures $\left(\sim 650^{\circ} \mathrm{C}\right)$, the $n$-value is high $(n=6.4 \pm 1.3)$. The

571 stress exponent of high-temperature experiments $\left(800-1000{ }^{\circ} \mathrm{C}\right)$ is $1.9 \pm 0.6$ (Fig. 13a)

572 and shows little variation with temperature. For high temperature experiments, the

573 activation energy is determined to be $\sim 170 \pm 72 \mathrm{~kJ} / \mathrm{mol}$ (Fig. 13b).

574 The highest stress values at $900{ }^{\circ} \mathrm{C}\left(499 \mathrm{br}\right.$ at $\left.\sim 10^{-3} \mathrm{~s}^{-1}\right)$ and $800{ }^{\circ} \mathrm{C}(447 \mathrm{br}$, fast step of 575488 br at $\sim 10^{-4} \mathrm{~s}^{-1}$; Fig. 4) are not included in the determination of the stress exponent 
576 and the activation energy because steady state is not indicated by the mechanical data.

\section{Insert Figure 13 here}

The calculated stress exponents confirm the transition from brittle-dominated

579 to viscous-dominated deformation at temperatures of $650 / 700{ }^{\circ} \mathrm{C}$, and strain rates of

$580 \sim 10^{-5} \mathrm{~s}^{-1}$. The stress exponent of $\sim 6.4$ of samples deformed at low temperatures (Fig.

581 13) is too high for dislocation creep deformation with typical values of $n=3-5$ (e.g.,

582 Karato, 2008; Paterson, 2013; Kohlstedt and Hansen, 2015), thus indicating the

583 beginning of the power-law breakdown, i.e., the lack of rate-controlling viscous

584 deformation at $\mathrm{T}<700{ }^{\circ} \mathrm{C}$. On the other hand, the $n$-values of 1.8 to 2 derived for

585 samples deformed at $T>700{ }^{\circ} \mathrm{C}$ (Fig. 13) are too low for dislocation creep, yet rather

586 high for diffusion creep.

587 Our determined Q-value of 168 to $170 \mathrm{~kJ} / \mathrm{mole}$ is very similar to values

588 determined by Jaoul et al. (1984) and lies in the range of other experimentally

589 determined values for dislocation creep (Table 4). Activation energies for diffusion

590 creep vary considerably and the values are highly dependent on the involved material

591 (silicon or oxygen diffusion) and the controlling process (transport or reaction) (e.g.,

592 137-178 kJ/mol for silicon diffusion in Farver and Yund, 2000; 142-243 kJ/mol for

593 oxygen diffusion in Giletti and Yund, 1984; $220 \mathrm{~kJ} / \mathrm{mol}$ in Rutter and Brodie, 2004a).

594 Hence, the range of previously determined activation energies and the precision of our

595 determination are inadequate to conclude decisively about the nature of the process

596 causing it. Rutter and Brodie, 2004a,b are the only studies that have determined

597 activation energies for both processes, and the values are very similar (Table 4). Based

598 on this evidence and our observations of a constant stress exponent of $n \sim 2$ between

$599800{ }^{\circ} \mathrm{C}$ to $1000^{\circ} \mathrm{C}$, we would like to maintain the idea that the activation energies of

600 contributing diffusion creep and dislocation creep mechanisms should be similar. 
602 A stress exponent $(n \sim 2)$ has been derived for deformation by dislocation-

603 accommodated grain-boundary sliding by, e.g., Kohlstedt and Hansen (2015).

604 However, the rather strong CPOs occurring in our samples argue against grain

605 boundary sliding (GBS). Although evidence exists for strong CPOs produced by GBS

606 (e.g., Schmid et al., 1987; Gomez Barreiro et al., 2007; Hansen et al., 2011), the

607 general consensus is that dominant GBS should produce weak CPOs (e.g., Edington et

608 al., 1976; Bell and Langdon, 1967). A possible explanation is a combination of

609 deformation processes, where dislocation creep produced strong CPOs and $n$-values of

6103 to 5 , in tandem with grain-size-sensitive diffusion creep, including grain boundary

611 sliding, which produced weak CPOs. Both together yield $n$-values of $\sim 2$.

612 To derive a grain-size exponent, we used samples 388br (standard), 419 (hot

613 pressed) and $445 \mathrm{br}$ (sieved to $7-11 \mu \mathrm{m}$ ), which were all deformed at $800{ }^{\circ} \mathrm{C}, 1.5 \mathrm{GPa}$

614 and $10^{-5} \mathrm{~s}^{-1}$, but yielded significantly different differential stresses. The grain size

615 exponent $p=\mathrm{m} / \mathrm{n}$, where $\mathrm{m}$ is the slope of the linear fit in the $\log$ (stress) versus

$616 \log$ (grain size) diagram (Fig. 13c) and $\mathrm{n}$ is the average stress exponent of 1.9. The

617 correlation coefficient for this fit is very low $(\mathrm{R}=0.258)$, and the value of $\mathrm{p}=1.08$ is

618 not well constrained. While our database is far too small for a reliable determination

619 of the grain size exponent, it is nevertheless interesting to note that similar uncertainty

620 is present in published data (Rutter and Brodie, 2004a).

623 The microstructural changes correspond to the transition conditions inferred

624 from the mechanical data. At strain rates of $\sim 10^{-5} \mathrm{~s}^{-1}$, the samples at $T \geq 700{ }^{\circ} \mathrm{C}$ show

625 features of dynamic recrystallisation, whereas at lower temperatures, Riedel fractures 
626 across grains are common (Figs. 6 and 7). The transition between brittle and viscous

627 microstructures is clearly visible between $650{ }^{\circ} \mathrm{C}$ and $700{ }^{\circ} \mathrm{C}$ at the strain rate of $\sim 10^{-5}$

$628 \mathrm{~s}^{-1}$ and confining pressures of 1.0 and $1.5 \mathrm{GPa}$. This observation is in excellent

629 agreement with the transition defined by mechanical data discussed above. The effect

630 of confining pressure becomes obvious in the microstructures at low confining

631 pressure of $0.5 \mathrm{GPa}$, where samples at $800{ }^{\circ} \mathrm{C}$ show predominantly brittle

632 microstructures (Fig. 8). The strain rate effect is not as clearly expressed in the

633 microstructure: At $650^{\circ} \mathrm{C}$, deformation at a strain rate of $\sim 10^{-6} \mathrm{~s}^{-1}$ produces similar

634 microstructures as a strain rate of $\sim 10^{-5} \mathrm{~s}^{-1}$ (cf. Figs. 6, 7). But at $\sim 10^{-5} \mathrm{~s}^{-1}$, clasts are

635 more rounded, and Riedel surfaces and shear bands are more pronounced. These

636 differences may well be due to the less total strain of the sample for a slower strain

637 rate. The faster strain rates at $800{ }^{\circ} \mathrm{C}$ and $900{ }^{\circ} \mathrm{C}$ yield microstructures that resemble a

638 mixture of microstructures at a strain rate of $\sim 10^{-5} \mathrm{~s}^{-1}$ between $600{ }^{\circ} \mathrm{C}$ and $700{ }^{\circ} \mathrm{C}$ (for

639 high shear strain): several remaining large clasts coexist with clusters of recrystallised

640 grains in a fabric dominated by shear bands (below referred to as "transitional").

641 At stresses above the Goetze criterion, typical regime 1 stress-strain curves

642 with pronounced weakening after peak stress (Hirth and Tullis (1992) are only

643 observed at $800^{\circ} \mathrm{C}$ and a strain rate of $\sim 2.5 \cdot 10^{-4} \mathrm{~s}^{-1}$ (Fig. 2). Bulging recrystallisation

644 concentrates along shear bands producing small new grains. After sufficient

645 recrystallisation, strain partitioning and weakening occur while mechanical and

646 microstructural steady state are not achieved. Below the Goetze criterion, generally at

647 higher temperatures and slower strain rates, minor strain weakening occurs, except at

$6481000{ }^{\circ} \mathrm{C}$ where steady state is attained (Fig. 2). The associated microstructure is

649 dominated by a pervasive shape foliation of recrystallised grains and the development

650 of a CPO. Hence, mechanical steady state is approached, but not perfectly realised, 
651 and this result is consistent with incomplete recrystallisation (Fig. 6), a switch from

652 one deformation mechanism to the next, or simultaneous operation of two

653 mechanisms.

\subsubsection{Misorientation density}

So as to distinguish recrystallised grains from potential survivor grains of the

658 original quartz material on the basis of some intragranular misorientation density, the

659 grain kernel average misorientation (gKAM) and the grain orientation spread

660 normalised with respect to the long axis $\left(\mathrm{GOS}_{\mathrm{la}}\right)$ were measured. We initially assumed

661 that low intragranular misorientation densities are characteristic of newly

662 recrystallised, recovered grains, whereas high misorientation densities are typical for

663 the original crushed material. However, it was found that recrystallising grains

664 continue to accumulate intragranular strain as the overall shear deformation continues.

665 Accordingly, the gKAM remains high and rather reflects grain-scale strain (Kilian and

666 Heilbronner, 2017). A correlation of high gKAM with small (recrystallized) grain size

667 has also been noted (Heilbronner and Kilian, 2017). In other words, the gKAM, or

668 any other measure of internal misorientation density, does not reflect recovery, and

669 therefore cannot be used to distinguish recrystallized grains from relict grains.

670 However, gKAM and GOS $_{\text {la }}$ do vary as a function of temperature: The higher

671 the deformation temperature, the smaller the intragranular misorientation density (Fig.

672 10). Pre-deformation hot pressing or sieving does not significantly influence this

673 trend. At lower temperatures, large grains with high PARIS factors (more lobate

674 grains) have higher gKAM and $\mathrm{GOS}_{\mathrm{la}}$ values than the small grains with low PARIS

675 factor (fully convex grains). In other words, large grains tend to have high 
676 misorientation densities while small grains display the full spectrum of misorientation

677 density, from fully recovered to highly strained. This distinction becomes

678 progressively smaller with increasing temperature, until, at $1000{ }^{\circ} \mathrm{C}$, all grains,

679 irrespective of shape and size, have very small misorientation densities, i.e., appear

680 fully recovered.

$681 \quad$ 5.5.2 CPO of diffusion and dislocation creep

682 To investigate if diffusion creep and dislocation creep are grain-size selective,

683 we consider the textures of the small and the large grain-size fractions separately (Fig.

684 11). Small and large grain-size fractions are delimited by the $3 \mathrm{D}$ mode which as a

685 result the number of grains in the smaller and larger fraction differ considerably. Pole

686 figures are therefore weighted by the area of the evaluated grains to avoid artefacts.

687 We also checked by comparing number-weighted pole figures that were calculated for

688 the large grain-size fraction and for the same number of randomly selected small

689 grains. The texture indices and the pole figure maxima of $[c],\langle a\rangle$, and $\langle r\rangle$ pole

690 figures of smaller grains are weaker than those for larger grains. The weaker textures

691 are consistent with diffusion creep mechanisms being active in the smaller grain size

692 fraction.

693 At $700{ }^{\circ} \mathrm{C}$, the weaker texture of the small grains is attributed to processes

694 such as solution precipitation and nucleation. At $800{ }^{\circ} \mathrm{C}$ and $900{ }^{\circ} \mathrm{C}$, textures of the

695 small grains are not only weakened but also the c-axis maxima are rotated with

696 respect to those of the large grains. For $800{ }^{\circ} \mathrm{C}$ and $900{ }^{\circ} \mathrm{C}$, the rotation is $20^{\circ}$ and $10^{\circ}$,

697 respectively, clockwise in the sense of the applied shear, compatible with grain-

698 boundary sliding and a stiff rotation of grains. At $1000{ }^{\circ} \mathrm{C}$, the difference between the

699 pole figures of the smaller and larger grain size fractions is the texture strength, not in

700 the texture type. As the rotation axis of the applied shear is parallel to the (strong) $c$ - 
701 axis maximum, a potential rotation is difficult to discern.

702 Comparing the experimental quartz deformation analysed here with results

703 derived from naturally or experimentally deformed quartzites, we find that the CPO

704 evolution of the larger grain-size fraction (Fig. 11) is consistent with observations

705 where high temperature deformation produces a central $c$-axis maximum, whereas low

706 temperature deformation (or small shear strains in experiments) produces peripheral

707 maxima (e.g., Schmid and Casey, 1986; Stipp et al., 2002; Heilbronner and Tullis,

$7082002,2006)$. In terms of the three microstructural regimes identified in nature, the 700

$709{ }^{\circ} \mathrm{C}$ and the $800{ }^{\circ} \mathrm{C}$ experiments would coincide with BLG (bulging), the $900{ }^{\circ} \mathrm{C}$

710 sample with SGR (subgrain rotation) and the $1000^{\circ} \mathrm{C}$ sample with GBM (grain

711 boundary migration). In a more recent study by Kilian and Heilbronner (2017), it was

712 found that the textures of Black Hills quartzite (BHQ) deformed in the dislocation

713 creep regimes 1,2 , and 3 , develop from a peripheral $c$-axis maximum towards a

714 central $c$-axis maximum as the result of a transition from dominant nucleation /

715 bulging recrystallisation to dominant subgrain rotation recrystallisation.

$716 \quad 5.5 .3$ Grain size distributions in diffusion and dislocation creep

717 In a mixed mode of diffusion creep and dislocation creep, as inferred here

718 from the stress exponents of $n \sim 2$, diffusion creep is expected to be more efficient in

719 small grains while dislocation creep, which is grain-size insensitive, should be more

720 active in larger grains (Tullis, 2002). An estimate for the upper grain-size limit of

721 grain-size-sensitive creep is given as $<1 \mu \mathrm{m}$ (Rutter and Brodie, 2004a), whereas Luan

722 and Paterson (1992) estimate the upper size limit to be $\sim 20 \mu \mathrm{m}$. The recrystallised

723 grain size measured for our experiments at $\mathrm{T}=800-1000{ }^{\circ} \mathrm{C}$, is well within these

724 limits: Recrystallised grain sizes range from $<1 \mu \mathrm{m}$ up to $25 \mu \mathrm{m}$, with modal values

725 (3D mode) of $\sim 4, \sim 6$ and $\sim 10 \mu \mathrm{m}$ for $800{ }^{\circ} \mathrm{C}, 900{ }^{\circ} \mathrm{C}$ and $1000^{\circ} \mathrm{C}$, respectively (Fig. 
726 9). As was shown, the partitioning of deformation mechanisms into smaller and larger

727 grain size fractions takes place in our samples for grain size below and above these

728 modal values as a threshold. Our threshold values are closer to the transition limit of

729 Luan and Paterson (1992) for dislocation and diffusion creep.

730 Before reaching the hit point, the original fractal grain-size distribution has

731 been modified by grain growth. We can estimate from the analysis of two hot-

732 pressed samples that the very smallest size fraction has been obliterated in a manner

733 described by Keulen et al. (2008) for healed faults. However, we do not know how

734 far grain growth proceeded during pressurization and heating, and what the smallest

735 grain size may be at the start of the experiment. In contrast, when the starting

736 material consists of a grain-size fraction of 7-11 $\mu \mathrm{m}$ (sample 445br), we know that

737 any grain smaller than $7 \mu \mathrm{m}$ must have formed during deformation, possibly by a

738 process such as bulging recrystallisation, nucleation (Kilian and Heilbronner, 2017),

739 or creep cavitation (Precigout and Stunitz, 2016). Comparing samples 445br

740 (sieved), 388br (standard) and 419br (hot pressed), we note that the grain sizes and

741 stress do not follow a piezometric relation. Grain sizes (3D modes) of 4.4, 4.1 and

$7424.8 \mu \mathrm{m}$ were measured for flow stresses of 309, 791 and $1016 \mathrm{MPa}$, respectively.

743 Rather than decreasing with grain size, stress seems to increase (cf. Fig. 13c). In

744 other words, the piezometer relation does not hold and pure dislocation creep can be

745 excluded, suggesting that a substantial contribution of diffusion creep has to be

746 inferred.

$748 \quad 5.6$ Using the Griggs apparatus for the derivation of stress exponents

749 As mentioned above, for dislocation creep in quartz, stress exponents of $n=3-$

7505 are often given in the literature (Gleason and Tullis, 1995; Luan and Paterson, 
751 1992, Hirth et al., 2001), despite the fact that lower values were determined

752 experimentally $(n \leq 2.5)$ in many cases (e.g., Jaoul et al., 1984; Kronenberg and

753 Tullis, 1984; Paterson and Luan, 1990; Rutter and Brodie, 2004b, see Table 4). For

754 some earlier data acquired with solid-medium apparatus, a large uncertainty is

755 attributed to imprecise stress measurements in the solid-medium deformation

756 apparatus (e.g., Gleason and Tullis, 1995). However, a large part of the lack of

757 precision and accuracy of the solid medium apparatus is caused by friction and errors

758 associated with the hit point determination. Strain-rate-stepping experiments should

759 not be affected by this error, because all data within a single experiment is determined

760 with respect to the same hit point, and only a slope is fitted to the data, regardless of

761 the absolute values of stresses. In addition, a recent study indicates good accuracy for

762 stresses derived from Griggs apparatus (Richter et al., 2016). Furthermore, the lack of

763 evidence for partial melting in our samples would be consistent with expected low

764 values for stress exponents as suggested by Jaoul et al., (1984); Luan and Paterson

765 (1992).

766 Stress exponents can only be correlated with deformation processes if steady

767 state conditions are reached. Achieving this state may be especially problematic for

768 regime 1 conditions (Hirth and Tullis, 1994). The required high strain conditions are

769 difficult to achieve in coaxial compression experiments. Our shear experiments are

770 deformed to high shear strain (up to $\gamma \sim 5$ ) where mechanical and microstructural

771 steady state is more or less achieved, at least at high temperatures $\left(800-1000{ }^{\circ} \mathrm{C}\right.$; Fig.

772 2). Hence, the low stress exponents cannot be explained by incomplete steady state

773 conditions as suggested by Gleason and Tullis (1995). In addition, Gleason and Tullis

774 (1995) associate low stress exponents with the transition from regime 2 to regime 1

775 after Hirth and Tullis (1992). Such a temperature dependent microstructural change is 
776 not observed in our samples used for calculating stress exponents. However, the

777 observed microstructures indicate dislocation creep and diffusion creep between 800

$778{ }^{\circ} \mathrm{C}$ and $1000{ }^{\circ} \mathrm{C}$. In contrast, dislocation creep was solely inferred in earlier studies

779 (e.g., Gleason and Tullis, 1995; Jaoul et al., 1984). These studies used quartzites with

780 narrow grain-size ranges and large average grain sizes where grain-size-sensitive

781 deformation mechanisms are unlikely. The broad grain-size range of our starting

782 material with a pronounced fine-grained fraction enables grain-size-sensitive diffusion

783 creep in addition to grain-size-insensitive dislocation creep resulting in mixed stress

784 exponents.

\subsection{Extrapolation to natural conditions}

It is important to attempt the extrapolation of experimental results to natural

788 conditions. As a first step, the different mechanical and microstructural criteria should

789 be combined to delineate the BVT. In the present study, sample deformation was

790 classified as viscous, semi-brittle, and transitional on the basis of the microstructural

791 suites and experimental behaviour, where transitional deformation is defined by the

792 presence of many remaining large clasts coexisting with clusters of recrystallised

793 grains, the fabric dominated by shear bands at high shear strain. Deformation

794 microstructures can be plotted for the same strain rate in a differential stress vs.

795 confining pressure diagram at a strain rate of $2.5 \cdot 10^{-5} \mathrm{~s}^{-1}$ (Fig. 14a). The transitional

796 samples all plot above the Goetze criterion, so that the Goetze criterion, as to be

797 expected, marks the upper stress limit of dominantly viscous deformation

798 mechanisms. For high confining pressures $(1.5 \mathrm{GPa})$, the BVT can be well delineated

799 using the microstructures and strain rate - temperature relationships (Fig. 14b),

800 although the Goetze criterion is more difficult to define at low temperatures. Using the 
801 broad division boundary (green line) from the experimental data, the BVT can be

802 extrapolated to natural conditions of strain rate and temperature (Fig. 14c). As can be

803 seen, the extrapolation is in fairly good agreement with the well documented BVT

804 data point of Stipp et al. $(2002 \mathrm{a}, \mathrm{b})$ for a strain rate of $\sim 10^{-12} \mathrm{~s}^{-1}$. For the representative

805 natural conditions $\left(280^{\circ} \mathrm{C}, P_{c}=300 \mathrm{MPa}, \Delta \sigma=250 \mathrm{MPa}\right)$, the stresses, which were

806 determined were converted to strain rates using the flow law from Hirth et al. (2001)

807 and recalculated for $1.5 \mathrm{GPa}$ confining pressure using the appropriate water fugacity

808 values. The microstructures of the Stipp et al. (2002a,b) sample at $280^{\circ} \mathrm{C}$ are within

809 the viscous field at stresses just below the brittle conditions, consistent with the

810 Goetze criterion and the extrapolation from this study. If natural conditions of $1.0 \mathrm{GPa}$

811 confining pressures are used, our corrected results for $P_{c}=1 \mathrm{GPa}$ and the Stipp et al.

812 (2002a,b) data are consistent, too (Fig. 14d). For 0.5 GPa confining pressure, our

813 experiments have only one data point, but it is also consistent with the extrapolation

814 derived from the series of experiments at higher pressure (Fig. 14d). Thus, this

815 extrapolation should serve as a guideline to determine the BVT in quartz for a wide

816 range of conditions between experiments and nature. For example, semibrittle

817 microstructures in rocks at elevated temperatures in quartz could be used to infer

818 minimum strain rates.

$819 \quad$ Insert Figure 14 here

820 If creep conditions of laboratory data for quartz are to be extrapolated to

821 natural conditions, a power-law behaviour (Eq. 1) is always assumed. Existing and

822 commonly used flow laws assume pure dislocation creep with a relatively high stress

823 exponent, typically $\mathrm{n}=4$ (Hirth et al., 2001; Paterson and Luan, 1990). Our flow law

824 parameter of a stress exponent of $n=1.9$ (Table 4) introduces combined (mixed

825 mode) deformation mechanisms of dislocation and diffusion creep. It should be 
826 pointed out that the stress exponent for silica gel in the experiments by Luan and

827 Paterson (1992) also show a value of $\mathrm{n}=2.3$, the data by Jaoul et al., (1984) show $\mathrm{n}$

$828=1.4$ to 2.4 , and Kronenberg and Tullis (1984) show $\mathrm{n}=2.5$ for novaculite. Thus,

829 several studies have determined stress exponents of $\mathrm{n} \approx 2$, independently from each

830 other. The reason why these stress exponents have been questioned in the past is that

831 either impurities (Luan and Paterson, 1992) or melt (Jaoul et al., 1984) may have

832 affected the rheology of the samples. In our case, no melt was detected, and we can

833 demonstrate the effect of smaller and larger grain-size fractions for the activation of

834 different deformation mechanisms. Our value for the activation energy is greater than

835 those of Hirth et al. (2001) and Kronenberg and Tullis (1984) and less than those of

836 Rutter and Brodie (2004) and Gleason and Tullis (1995), but the range of values is

837 consistent with previous determinations (Table 4).

838 When our data are extrapolated to low temperatures at natural strain rates, the

839 BVT in terms of temperature, strain rate, and pressure will very much depend on the

840 grain size, where small sizes that are very common at low temperatures will favour the

841 operation of diffusion creep mechanism, which are part of the inferred deformation

842 mechanisms in this study. In nature, the expected deformation process probably is

843 solution precipitation creep. It is an important result of this study that the BVT in

844 quartz is not simply a transition from cracking to crystal-plastic deformation, but,

845 instead, it involves grain-size dependent diffusion-creep processes, too.

846 Cataclasis is a very efficient process to reduce grain size, so that our simulated

847 cataclasite is an appropriate starting material for studying the deformation history

848 dependent transition from cracking to viscous deformation. The results clearly show

849 that cataclasites are very likely candidates for subsequent viscous deformation. This

850 interplay of brittle and viscous deformation processes is particularly applicable to high 
851 stress deformation settings such as seismically active deformation zones. Catclasis

852 will provide the fine-grained material, which helps to accommodate aseismic creep in

853 interseismic periods, i.e., postseismic creep deformation.

\section{Conclusions}

856 A set of shear experiments performed on quartz material under elevated

857 confining pressures (predominantly $1.5 \mathrm{GPa})$ and temperatures $\left(500{ }^{\circ} \mathrm{C}-1000{ }^{\circ} \mathrm{C}\right)$ at

858 intermediate to fast shear strain rates $\left(3.5 \cdot 10^{-6} \mathrm{~s}^{-1}\right.$ to $\left.\sim 2 \cdot 10^{-3} \mathrm{~s}^{-1}\right)$ documents the

859 transition from (semi)-brittle to viscous deformation. The Goetze criterion $\left(\Delta \sigma>P_{c}\right)$ is

860 confirmed to delineate the upper limit of differential stress for viscous deformation.

861 Samples above the Goetze criterion are characterised by Riedel fractures or

862 shear bands at high shear strain, normal geological friction coefficients, and $n$-values

863 too high for dislocation creep. At low temperatures, increasing confining pressure

864 causes increasing strength, as is to be expected for fracturing and frictional

865 deformation. A somewhat unsystematic temperature-dependence of stress is observed

866 under these conditions. Cataclastic flow partly accompanied by stress-induced

867 dissolution precipitation is suggested as the dominating deformation process at

868 temperatures just below the transition to viscous deformation $\left(650^{\circ} \mathrm{C}\right)$ for a strain rate

869 of $2.5 \times 10^{-5} \mathrm{~s}^{-1}$, indicated by a power-law breakdown with a stress exponent of $n=6.4$

$870 \pm 1.3$

871 Below the Goetze criterion $\left(\Delta \sigma<P_{c}\right)$, viscous deformation dominates, as

872 demonstrated by weakening of samples with increasing pressure and temperature. The

873 microstructure is dominated by a pervasive foliation at high shear strain accompanied

874 by an increasing recrystallised grain size with increasing temperature, only partially

875 dependent on flow stress. Presence of different CPO's in different grain-size fractions 
876 and the stress exponents $(n=1.9 \pm 0.6)$ indicate a combination of diffusion creep and

877 dislocation creep. It is argued that diffusive mass transfer and grain-boundary-sliding

878 prefer the small grain-size fraction while dislocation creep is more effective in large

879 grains. The constant stress exponent between $800{ }^{\circ} \mathrm{C}$ and $1000{ }^{\circ} \mathrm{C}$ suggests no change

880 in the rate-limiting factor and a similar activation energy for the diffusion and

881 dislocation creep mechanism.

882 From these results, it can be inferred that the brittle to viscous transition with

883 increasing temperature in nature may occur as a combination of diffusion and

884 dislocation creep. The combination favours the viscous deformation to occur in fine

885 grained aggregates likely to have formed by previous cataclastic deformation. Such a

886 sequential transition in time elegantly explains the alternation of episodic seismic

887 (brittle) and aseismic deformation in high stress, seismically active zones.

888

889

Acknowledgments

890 We would like to thank Rüdiger Kilian for extensive stimulating discussions

891 and help with the MTEX toolbox. Furthermore, we wish to thank Willy Tschudin for

892 preparing excellent thin sections, Hans-Rudolf Rüegg for supplying equipment in the

893 deformation lab, Trine Merete Dahl for preparing thin sections for EBSD, and the

894 team of the Nano Imaging Lab and Tom Ivar Eilertsen for support with the SEM. Raw

895 data and samples can be acquired at the corresponding author. Constructive and

896 insightful reviews of 2 anonymous reviewers and Raphael Gottardi and he very

897 constructive input by the editor William Dunne have substantially improved the

898 manuscript. Funding by the Swiss National Science Foundation grant no. 200021-

899138216 is thankfully acknowledged.

900 
902 Barber, D. J., Wenk, H.-R., Hirth, G., Kohlstedt, D. L. (2010) Dislocations in

903 minerals In: Hirth, J. P., Kubin, L. (Ed.) Dislocation in solids, Elsevier, 171-232,

904 doi:10.1016/SI572-4859(09)01604-0

905 Bell, R. L., Langdon, T. G. (1967) An investigation of grain-boundary sliding

906 during creep, Journal of Material Science, 2, 313-323

907 Berthé, D, Choukroune, P., Jegouzo, P. (1979) Orthogneiss, mylonite and non

908 coaxial deformation of granites: the example of the South Armorican Shear Zone,

909 Journal of Structural Geology, 1, 31-42

910 Blanpied, M. L., Lockner, D. A., Byerlee, J. D., (1995) Frictional slip of

911 granite at hydrothermal conditions, Journal of Geophysical Research, 100, 13045-

91213064

913 Brace, W. F., Kohlstedt, D. L. (1980) Limits on lithospheric stress imposed by

914 laboratory experiments, Journal of Geophysical Research: Solid Earth, 85, 6248-6252

915 Byerlee, J. D. (1968) Brittle-ductile transition in rocks, Journal of Geophysical

916 Research, 73, 4741-4750

917 Byerlee, J. (1978) Friction of Rocks, Pure and Applied Geophysics, 116, 615-

918 626, doi:10.1007/BF00876528

919 Chester, F M., Higgs, N. G. (1992) Multimechanism friction constitutive

920 model for ultrafine quartz gouge at hypocentral conditions, Journal of Geophysical

921 Research, 97, 1859-1870

922 Cross, A. J., Priop, D. J., Stipp, M., Kidder, S. (2017) The recrystalliued grain

923 size piezometer for quartz: An EBSD-based calibration, Geophysical Research

924 Letters, 44, 6667-6674, doi:10.1002/2017GL073836 
925 Edington, J. W., Melton, K. N., Cutler, C. P. (1976) Superplasticity, Progress

926 in Material Science, 21, 61-158

927 FitzGerald, J. D., Boland, J. N., McLaren, A. C., Ord, A., Hobbs, B. E. (1991)

928 Microstructures in water-weakened single crystals of quartz, Journal of Geophysical

929 Research, 96, 2139-2155

930 Farver, J., and Yund, R. (2000) Silicon diffusion in a natural quartz aggregate:

931 constraints on solution-transfer diffusion creep, Tectonophysics, 325, 193-205

932 Giletti, B. J., and Yund, R. A. (1984) Oxygen diffusion in quartz, Journal of

933 Geophysical Research, 89, 4039-4046

934 Gleason, G. C., and Tullis, J. (1995) A flow law for dislocation creep of quartz

935 aggregates determined with the molten salt cell, Tectonophysics, 247, 1-23

936 Gomez Barreiro, J., Lonardelli, I., Wenk, H. R., Dresen, G., Rybacki, E.,

937 Tomé, C. N. (2007) Preferred orientation of anorthite deformed experimentally in

938 Newtonian creep, Earth and Planetary Science Letters, 264, 188-207

939 Handy, M. R. (1989) Deformation regimes and the rheological evolution of

940 fault zones in the lithosphere: the effects of pressure, temperature, grainsize and time,

941 Tectonophysics, 163, 119-152

942 Hansen, L. N., Zimmerman, M. E., Kohlstedt, D. L. (2011) Grain boundary

943 sliding in San Carlos olivine: Flow law parameters and crystallographic-preferred

944 orientation, Journal of Geophysical Research, 116, B08201,

945 doi:10.1029/2011JB008220

946 Heilbronner, R., and Barrett, S. (2014) Image analysis in earth sciences,

947 Springer Berlin Heidelberg, p. 520 
Heilbronner, R., and Kilian, R. (2017) The grain size(s) of Black Hills

949 Quartzite deformed in the dislocation creep regime, Solid Earth,

950 https://doi.org/10.5194/se-8-1071-2017

951 Heilbronner, R., and Tullis, J. (2002) The effect of static annealing on

952 microstructures and crystallographic preferred orientations of quartzites

953 experimentally deformed in axial compression and shear, Geological Society, London,

954 Special Publications, 200, 191-218, doi:10.1144/GSL.SP.2001.200.01.12

955 Heilbronner, R., and Tullis, J. (2006) Evolution of c axis pole figures and grain

956 size during dynamic recrystallization: Results from experimentally sheared quartzite,

957 Journal of Geophysical Research, 111, B10202, doi:10.1029/2005JB004194

958 Hielscher, R., and Schaeben, H. (2008) A novel pole figure inversion method:

959 specification of the MTEX algorithm, Journal of Applied Crystallography, 41, 1024-

960 1037, doi:10.1107/S0021889808030112

961 Hirth, G., Teyssier, C., Dunlap, W. J. (2001) An evaluation of quartzite flow

962 laws based on comparisons between experimentally and naturally deformed rocks,

963 International Journal of Earth Science, 90, 77-87, doi:10.1007/s005310000152

964 Hirth, G., and Tullis, J. (1992), Dislocation creep regimes in quartz aggregates,

965 Journal of Structural Geology, 14, 145-159, doi:10.1016/0191-8141(92)90053-Y

966 Hirth, G., and Tullis, J. (1994), The brittle-plastic transition in experimentally

967 deformed quartz aggregates, Journal of Geophysical Research, 99, 11731-11747,

968 doi:10.1029/93JB02873

969 Jaoul, O., Tullis, J., Kronenberg, A. (1984) The effect of varying water

970 contents on the creep behaviour of Heavitree quartzite, Journal of Geophysical

971 Research, 89, 4298-4312 
973 of seismic anisotropy of the upper mantle: new insights from laboratory studies,

974 Annu. Rev. Earth Planet. Science, 36, 59-95,

975 doi:10.1146/annurev.earth.36.031207.124120

976 Keulen, N., Stünitz, H., Heilbronner, R. (2008): Healing microstructures of

977 experimental and natural fault gouge. - J. Geophys. Research,

978 doi:10.1029/2007JB005039

979 Kilian, R., and Heilbronner, R. (2017) Texture analysis of experimentally

980 deformed Black Hills Quartzite, Solid Earth, https://doi.org/10.5194/se-8-1095-2017

981 Kohlstedt, D. L., Evans, B., Mackwell, S. J. (1995) Strength of the lithosphere:

982 Constraints imposed by laboratory experiments, Journal of Geophysical Research, 983 100, 17,587-17,602, doi:10.1029/95JB01460

984 Kohlstedt, D. L., and Hansen, L. N., (2015) Constitutive equations, rheological 985 behaviour, and viscosity of rocks, In: Schubert, G. (Ed.) Treatise on geophysics, $2^{\text {nd }}$ 986 edition, Vol. 2, Oxford: Elsevier, 441-472

987 Kronenberg, A. K., and Tullis, J. (1984) Flow Strengths of Quartz Aggregates:

988 Grain Size and Pressure Effects due to Hydrolytic Weakening. Journal of Geophysical 989 Research, 89, 4281-4297, doi:10.1029/JB089iB06p04281

990 Luan, F. C., and Paterson, M. S. (1992) Preparation and deformation of

991 synthetic aggregates of quartz, Journal of Geophysical Research, 97, 301-320

992 Menegon, L., Pennachioni, G., Heilbronner, R., Pittarello, L. (2008) Evolution

993 of quartz microstructure and $c$-axis crystallographic preferred orientation within

994 ductilely deformed granitoids (Arolla unit, Western Alps), Journal of Structural

995 Geology, 30, 1332-1347, doi:10.1016/j.jsg2008.07.007 
Orowan, E. (1940) Problems of plastic gliding, Proceedings of the Physical

997 Society, 52, 8-22

998 Panozzo, R., and Hürlimann, H. (1983) A simple method for the

999 discrimination of convex and convex-concave lines, Microscopica Acta, 87, 169-176

1000 Paterson, M. S. (1989) The interaction of water with quartz and its influence in

1001 dislocation flow - an overview, In: Karato, S.-I., and Toriumi, M. (Ed.), Rheology of

1002 solids and of the earth, Oxford Univiversity Press, Oxford, 107-142

1003 Paterson, M. S. (2013) Materials science for structural geology, Springer

1004 Dordrecht Heidelberg New York London, p. 247, doi:10.1007/978-94-007-5545-1

1005 Paterson, M. S., and Luan, F. C. (1990) Quartzite rheology under geological

1006 conditions, In: Knipe, R. J., Rutter, E. H. (eds.), Deformation mechanisms, rheology

1007 and tectonics, Geological Society Special Publication, 54, 299-307

1008 Paterson, M. S., and Wong, T. (2005) Experimental rock deformation - the

1009 brittle field, Springer Berlin Heidelberg, p. 347, doi:10.1007/b137431

1010 Pec, M., Stünitz, H., Heilbronner, R. (2012) Semi-brittle deformation of

1011 granitoid gouges in shear experiments at elevated pressures and temperatures, Journal

1012 of Structural Geology, 33, 200-221, doi:10.1016/j.jsg.2011.09.001

1013 Pec, M. (2014), Experimental investigation on the rheology of fault rocks,

1014 dissertation, Basel Universität, Basel

1015 Poirier, J.P., and Guillope, M. (1979) Deformation induced recrystallization of

1016 minerals, Bull. De. Mineral. 102, 67-74.

1017 Précigout, J., Stünitz, H. (2016): Evidence of phase nucleation during olivine

1018 diffusion creep: A new perspective for mantle strain localization. - Earth and

1019 Planetary Science Letters, 455, p. 94-115, doi.org/10.1016/j.epsl.2016.09.029 
Richter, B, Stünitz, H., Heilbronner, R. (2016) Stresses and pressures at the

1021 quartz-to-coesite transformation in shear deformation experiments, Journal of

1022 Geophysical Research: Solid Earth, 121, doi:10.1002/2016JB013084

1023 Rutter, E. H., and Brodie, K. H. (2004a) Experimental grain size-sensitive flow

1024 of hot pressed Brazilian quartz aggregates, Journal of Structural Geology, 26:11,

$1025 \quad 2011-2023$

1026 Rutter, E. H., and Brodie, K. H. (2004b) Experimental intracrystalline plastic

1027 flow in hot pressed synthetic quartzite prepared from Brazilian quartz crystals, Journal

1028 of Structural Geology, 26, 259-270, doi: 10.1016/S0191-8141(03)00096-8

1029 Schmid, S. M., and Casey, M. (1986) Complete fabric analysis of some

1030 commonly observed quartz c-axis patterns, Geophysical Monographs, 36, 263-286

1031 Schmid, S. M., Panozzo, R., Bauer, S. (1987) Simple shear experiments on

1032 calcite rocks: rheology and microfabric, Journal of Structural Geology, 9, 747-778

1033 Scholz, C. H. (2007) The Mechanics of Earthquakes and Faulting, $2^{\text {nd }}$ edition,

1034 Cambridge University Press, Cambridge, p. 471

1035 Sibson, R. H. (1989) Earthquake faulting as a structural process, Journal of

1036 Structural Geology, 11, 1-14, doi:10.1016/0191-8141(89)90032-1

1037 Stipp, M., Stünitz, H., Heilbronner, R., Schmid, S. M. (2002a) Dynamic

1038 recrystallisation of quartz: correlation between natural and experimental conditions,

1039 Geological Society, London, Special Publications, 200, 171-190,

1040 doi:10.1144/GSL.SP.2001.200.01.11

1041 Stipp, M., Stünitz, H., Heilbronner, R. \& Schmid, S. M. (2002b):

1042 DynamicRecrystallization of quartz: Correlation between Natural and Experimental

1043 Conditions. In: S. de Meer, M. R. Drury, J. H. P. de Bresser \& G. M. Pennock:

1044 Deformation Mechanisms, Rheology and Tectonics: Current Status and Future 
1045 Perspectives. - Geological Society, London, Special Publications 200, 171-190.

1046 Stünitz, H., Thust, A., Behrens, H., Kilian, R., Tarantola, A., FitzGerald, J. D.

1047 (2017) Water redistribution in experimentally deformed natural milky quartz single

1048 crystals - Implications for $\mathrm{H}_{2} \mathrm{O}$-weakening processes, Journal of Geophysical

1049 Research: Solid Earth, 122, doi:10.1002/2016JB013533

1050 Tarantola, A., Diamond, L. W., Stünitz, H. (2010) Modification of fluid

1051 inclusions in quartz by deviatoric stress I: experimentally induced changes in

1052 inclusion shapes and microstructures, Contribution to mineralogy and Petrology, 160,

1053 825-843, doi:10.1007/s00410-101-0509-z

1054 Tarantola, A., Diamond, L. W., Stünitz, H., Thust, A., Pec, M. (2012)

1055 Modification of fluid inclusion in quartz ba deviatoric stress III: Influence of principal

1056 stresses on inclusion density and orientation, Contribution to Mineralogy and

1057 Petrology, 164, 537-550, doi:10.1007/s00410-012-0749-1

1058 Trepmann C. A., and Stöckhert B. (2003) Quartz microstructures developed

1059 during non-steady state plastic flow at rapidly decaying stress and strain rate, Journal

1060 of Structural Geology, 25. 2035-2051, doi:10.1016/S0191-8141(03)00073-7

1061 Trepmann, C. A., Stöckhert, B. (2013) Short-wavelength undulatory extinction

1062 in quartz recording coseismic deformation in the middle crust - an experimental

1063 study, Solid Earth, 4, 263-276, doi:10.5194/se-4-263-2013

1064 Tullis, J. (2002) Deformation of granictic rocks: Experimental studies and

1065 natural examples In: Karato, S.I. and Wenk, H.-R., Plastic deformation of minerals

1066 and rocks, Reviews in mineralogy and Geochemistry, 51, 51-95,

1067 doi:10.2138/gsrmg.51.1.51 
1069 strength: implications for hydrolytic weakening, Bulletin de Minéralogie, 102, 110-

$1070 \quad 114$

1071 Tullis, J., and Yund, R.A. (1977) Experimental deformation of dry Westerly

1072 granite, Journal of Geophysical Research, 82, 5705-5718

1073 Twiss, R. J., and Moores, E. M. (2007) Structural geology, W. H. Freeman and

1074 Company, New York, Second Edition, p. 736

1075 Van Daalen, M., Heilbronner, R., Kunze, K. (1999) Orientation analysis of

1076 localized shear deformation in quartz fibres at the brittle-ductile transition,

1077 Tectonophysics, 303, 83-107

1078 Yund, R.A., and Tullis, J. (1991) Compositional changes of minerals

1079 associated with dynamic recrystallisation, Contributions to Mineralogy and Petrology, $1080 \quad 108,346-355$

1081

1082

$1083 \quad$ Figures and tables

$1084 \quad$ Figure 1: Sample assembly.

1085 (a) Sample (quartz powder) is inserted between $45^{\circ}$ pre-cut forcing blocks, in a 1086 jacket surrounded by confining medium $(\mathrm{NaCl})$ and a carbon furnace (after Richter et $1087 a l ., 2016)$. Displacement in the shear zone is at $45^{\circ}$ to the plane of drawing. (b)

1088 Stresses in the sample: $F=$ load applied to upper forcing block, $P_{c}=$ confining

1089 pressure, $\sigma_{n}=$ normal stress, $\tau=$ shear stress.

1090

Figure 2: Stress-strain curves for constant shear strain rate experiments. 
1093 Shear experiments at different temperatures; arrow indicates assumed initiation of slip

1094 at sample - forcing block interface. (b) Experiments with different shear strain rates at

$1095650{ }^{\circ} \mathrm{C}, 800{ }^{\circ} \mathrm{C}$ and $900{ }^{\circ} \mathrm{C}$. (c) Experiments with different starting material: crushed

1096 = gouge $(\mathrm{d} \leq 100 \mu \mathrm{m})$; hot pr. = gouge $(\mathrm{d} \leq 100 \mu \mathrm{m})$, hot pressed before deformation

$1097\left(20 \mathrm{~h}\right.$ at $\left.1000^{\circ} \mathrm{C}, 1.5 \mathrm{GPa}\right)$; sieved $=$ gouge $(7 \leq \mathrm{d} \leq 11 \mu \mathrm{m})$; arrow indicates the onset

1098 of forcing block deformation.

$1100 \quad$ Figure 3: Stress-strain curves to demonstrate the influence of confining

1101 pressure at three different temperatures.

1102 Strain rate is $2.5 \cdot 10^{-5} \mathrm{~s}^{-1}$; horizontal lines mark the Goetze criterion for

1103 different confining pressures.

Figure 4: Stress-strain curves for strain rate stepping experiments.

$1107800{ }^{\circ} \mathrm{C}$ (hot pressed; dashed line as in Fig. 2) are shown in comparison with constant

1108 shear strain rate experiments (numbers 500br, 499br, 412br, 388br, 337br, 419br) at

1109 same conditions. Confining pressure is $1.5 \mathrm{GPa}$ in all samples; horizontal lines mark

1110 the Goetze criterion. The arrow at $488 \mathrm{br}\left(800{ }^{\circ} \mathrm{C}\right)$ points to a failure of the experiment.

1111 The arrow at $482 \mathrm{br}\left(900^{\circ} \mathrm{C}\right)$ at very high strain marks the change of sample geometry

1112 due to collision of forcing blocks.

1113

$1114 \quad$ Figure 5: Starting material.

1115 Quartz powder after run-in of the $\sigma_{1}$ piston but before the hit point (pre-

1116 deformation) at $800{ }^{\circ} \mathrm{C}$ and $1000{ }^{\circ} \mathrm{C}$. (a) Light micrograph of sample $487 \mathrm{br}$ at

$1117 \mathrm{~T}=800^{\circ} \mathrm{C}$ and $\mathrm{Pc}=1.5 \mathrm{GPa}$, total time of experiment: $25 \mathrm{~h}$. Look-up table in upper right 
1118 indicates circular polarisation. (b) SEM/band contrast image of sample 487br. (c)

1119 Light micrograph of sample $417 \mathrm{br}$ at $\mathrm{T}=1000^{\circ} \mathrm{C}$ and $\mathrm{Pc}=1.5 \mathrm{GPa}$, total time of

1120 experiment: 20h. Look-up table in upper right indicates crossed polarisation. (d)

1121 SEM/band contrast image of sample 417br. SEM and light micrographs do not show

1122 the same regions.

1123

1124 Figure 6: Microstructures across the brittle-to-viscous transition.

1125 High strain samples deformed at temperatures between $500{ }^{\circ} \mathrm{C}$ and $1000^{\circ} \mathrm{C}$,

$11261.5 \mathrm{GPa}$ and $\sim 10^{-5} \mathrm{~s}^{-1}$. Look-up tables indicate circular polarisation for all

1127 micrographs, except 450br and 435br which are cross polarised; sinistral shear sense

1128 applies to all. Left two columns: experiments using crushed starting material, right

1129 column: experiments with hot pressed starting material. Solid lines (F) indicate

1130 orientation of foliation; dashed lines indicate shear band orientation (SB); dotted lines

1131 mark Riedel surfaces ( $\mathrm{R}$ and R'), schematic of Riedel geometry in inset lower right.

$1133 \quad$ Figure 7: Dependence of microstructures on confining pressure and strain rate.

1134 Look-up tables indicate circular polarisation or crossed polarisation; sinistral

1135 shear sense applies to all. Solid lines (F) indicate orientation of foliation; dashed lines

1136 indicate shear band orientation (SB); dotted lines mark Riedel surfaces (R).

$1138 \quad$ Figure 8: Brittle structures at high temperature.

1139 Sample (386br) deformed at $800^{\circ} \mathrm{C}, 0.5 \mathrm{GPa}$ and $\sim 10^{-5} \mathrm{~s}^{-1}$. (a) Light

1140 micrograph showing fracturing; look-up tables indicate crossed polarisation; dotted

1141 lines mark Riedel surfaces ( $R$ and $\left.R^{\prime}\right)$. (b) SEM/BSE micrograph of very fine-grained

1142 material generated by comminution along Riedel fractures. 
$1144 \quad$ Figure 9: Grain size distribution of recrystallised grains.

$1145 \quad$ Histograms show volume weighted frequency distributions of the diameter of

1146 volume equivalent spheres $\left(\mathrm{D}_{\text {equ }}\right)$; modal values are indicated. Grain size maps for

1147 samples deformed between $700^{\circ} \mathrm{C}$ and $1000^{\circ} \mathrm{C}$ are shown with the same magnification

1148 (see scale) and color coded such that blue to yellow corresponds to $2 \mu \mathrm{m} \leq \mathrm{D} \leq 9 \mu \mathrm{m}$.

1149 (a) Grain size distributions for standard starting material $(\mathrm{d} \leq 100 \mu \mathrm{m})$. (b) Special

1150 starting material for comparison: hot pr. = hot pressed before deformation; sieved =

$1151 \quad$ starting material $(7 \leq \mathrm{d} \leq 11 \mu \mathrm{m})$.

Figure 10: Internal misorientation density of recrystallised grains.

1155 samples deformed at temperatures from $700{ }^{\circ} \mathrm{C}$ to $1000{ }^{\circ} \mathrm{C}$; gKAM $=$ grain kernel

1156 average misorientation (Heilbronner and Kilian, 2017); $\mathrm{GOS}_{\mathrm{la}}=$ grain orientation

1157 spread, normalised for long axis (see text); for each data point, the PARIS factor is

1158 colour coded and the symbol size is related to the equivalent diameter.

$1160 \quad$ Figure 11: Textures for different grain size fractions.

1161 Textures are shown for samples with standard starting material (crushed),

1162 deformed at $700{ }^{\circ} \mathrm{C}$ to $1000{ }^{\circ} \mathrm{C}$, standard confining pressure of $1.5 \mathrm{GPa}$, and standard

1163 strain rate of $2.5 \cdot 10^{-5} \mathrm{~s}^{-1}$. For each temperature, $[c],[a]$, and $[r]$ pole figures are shown

1164 for all recrystallised grains in the range of $(d \leq 25 \mu \mathrm{m})$ (top row), for the small grain

1165 size fraction (middle row) and the large grain size fraction (bottom row); the

1166 delimiting grain size is indicated. Contouring interval $=1$ m.u.d.; pole figure

1167 maximum in the upper left and pole figure J-index on the lower right of the pole 
1168 figure.

Figure 12: Friction coefficients for different experimental conditions.

1171 Friction coefficient is calculated from shear and normal stress on sample: $\mu=$

$1172 \tau / \sigma_{n}$ (Figure 1). (a) Different shear strain rates at constant confining pressure of 1.5

1173 GPa. (b) Different confining pressures at constant shear strain rate of $2.5 \cdot 10^{-5} \mathrm{~s}^{-1}$.

Figure 13: Derivation of stress exponent and activation energy.

(a) At $650{ }^{\circ} \mathrm{C}$, the stress exponent $\mathrm{n} \sim 6.4$. For $800{ }^{\circ} \mathrm{C}-1000{ }^{\circ} \mathrm{C}$, the average of

1177 the stress exponent is determined: $n=1.9 \pm 0.6$. (b) From experiments at strain rates of

$117810^{-4} \mathrm{~s}^{-1}$ and $10^{-5} \mathrm{~s}^{-1}$, the activation energy is derived: $\mathrm{Q} \sim 170 \mathrm{~kJ} / \mathrm{mol}$. (II) indicates the

1179 second measurement of stress at a given strain rate in strain rate stepping experiments

1180 (cf. Table 2). (c) At $800^{\circ} \mathrm{C}, 1.5 \mathrm{GPa}$ and $10^{-5} \mathrm{~s}^{-1}$, and for a stress exponent $\mathrm{n}=1.9$, the

1181 grain size exponent $\mathrm{p}$ is $1.08 ; \mathrm{m}=$ slope of liner fit. Samples used: $388 \mathrm{br}=$ standard

1182 starting material; $419 \mathrm{br}=$ hot pressed at $1000^{\circ} \mathrm{C} ; 445 \mathrm{br}=$ sieved to $(7 \leq \mathrm{d} \leq-11 \mu \mathrm{m})$.

Figure 14: Extrapolation of the brittle-to-viscous transition from the lab to

1185 nature.

1186 Discrimination of 'brittle', 'transitional' and 'viscous' is based on

1187 microstructure. (a) Differential stress versus confining pressure for experimental

1188 samples and one natural samples. (b) Shear strain rate versus temperature for

1189 experimental samples deformed at constant confining pressure; black numbers $=$ flow

1190 stress; grey numbers = peak stress; green line traces the brittle-to-viscous transition

1191 (BVT). (c) Extrapolation of (b) to natural conditions. The transition of a natural

1192 sample (Stipp et al. (2002)) is indicated; water fugacity is considered after Hirth et al., 
1193 (2001). (d) Same extrapolation as in (c) using additional data points recalculated for

$1194 \quad$ 1.0 GPa (orange) and 0.5 GPa (blue) confining pressure; filled circles - using flow

1195 law after Hirth et al., 2001; open circles - using flow law of this study.

1198 Table 1: Experimental conditions for constant shear strain rate experiments.

1199 1) Pre-treatment: Hot pressed $=20$ hours at $1000^{\circ} \mathrm{C}$ and $1.5-1.6 \mathrm{GPa}$. Sieved $=$ powder

$1200 \quad$ sieved to grain size fraction $(7 \leq \mathrm{d} \leq 11 \mu \mathrm{m})$.

1201 2) Friction coefficient determined at peak stress.

1202

1203 Table 2: Experimental conditions for shear strain rate stepping experiments.

1204 1) Temperature approximate due to technical problem with furnace.

1205 2) Approximate value due to power failure.

1206 3) Sample hot pressed for 20 hours at $1000^{\circ} \mathrm{C}$ and $1.5-1.6 \mathrm{GPa}$.

1207 4) Hardening at end of experiment due to contact of forcing blocks.

1208

$1209 \quad$ Table 3: Grain size analysis

1210 1) Arithmetic mean of area equivalent diameters of circles $\left(\mathrm{d}_{\mathrm{equ}}\right)$

1211 2) Median of $d_{\text {equ }}$

1212 3) Root-mean-square of $d_{\text {equ }}$

1213 4) Mode = Mean of Gaussian curve fit to volume weighted histogram of volume

1214 equivalent diameters of spheres $\left(D_{\text {equ }}\right)$

1215 5) Standard deviation of Gaussian curve fit.

1216 6) Hot pressed (24 h) undeformed sample

1217 7) Hot pressed (20 h) undeformed sample 
1218 8) Hot pressed (20 h) at $1000^{\circ} \mathrm{C}$ and 1.5-1.6 GPa.

1219 9) Powder sieved to grain size fraction $(7 \leq \mathrm{d} \leq 11 \mu \mathrm{m})$.

1220

1221 Table 4: Selection of flow law parameters from literature.

1222 


\begin{tabular}{|c|c|c|c|c|c|c|c|c|}
\hline Sample & $\begin{array}{c}\text { Temperature } \\
\left({ }^{\circ} \mathrm{C}\right)\end{array}$ & $\begin{array}{l}\text { Confining } \\
\text { Pressure } \\
(\mathrm{MPa})\end{array}$ & $\begin{array}{l}\text { Pre- } \\
\text { treatment }^{1)}\end{array}$ & Shear strain & $\begin{array}{c}\text { Shear strain } \\
\text { rate } \\
\left(\mathrm{s}^{-1}\right)\end{array}$ & $\begin{array}{c}\text { Maximum } \\
\text { differential stress } \\
(\mathrm{MPa})\end{array}$ & $\begin{array}{l}\text { Friction coefficient } \\
\left(\mu=\tau / \sigma_{n}\right) \text { at } \gamma=3\end{array}$ & $\begin{array}{l}\text { Microstructure } \\
\quad(\text { for } \gamma>3)\end{array}$ \\
\hline $340 b^{2)}$ & 500 & 1510 & & 1.6 & 1.4 & 2738 & 0.47 & - \\
\hline $450 \mathrm{br}$ & 500 & 1540 & & 3.2 & 2.1 & 3212 & 0.46 & brittle \\
\hline $338 b^{2)}$ & 600 & 1522 & & 1.4 & 1.4 & 2513 & 0.45 & - \\
\hline $479 \mathrm{br}$ & 600 & 1538 & & 3.9 & 2.1 & 2423 & 0.43 & brittle \\
\hline $415 \mathrm{br}$ & 600 & 1512 & hot pressed & 3.0 & 1.9 & 3246 & 0.51 & brittle \\
\hline $435 \mathrm{br}$ & 650 & 1507 & & 3.6 & 2.1 & 2698 & 0.46 & transitional \\
\hline $481 \mathrm{br}$ & 650 & 1554 & & 4.2 & 3.0 & 2538 & 0.43 & transitional \\
\hline $380 \mathrm{br}$ & 700 & 1500 & & 0.0 & 0.0 & 0 & 0.00 & - \\
\hline $339 b^{2)}$ & 700 & 1524 & & 2.0 & 2.1 & 1298 & 0.30 & - \\
\hline $437 b^{2)}$ & 700 & 1529 & & 1.7 & 1.9 & 1483 & 0.32 & - \\
\hline $383 b r$ & 700 & 1585 & & 4.9 & 2.8 & 1246 & 0.25 & viscous \\
\hline $493 b r$ & 700 & 1512 & hot pressed & 4.9 & 2.7 & 2051 & 0.39 & transitional \\
\hline $487 \mathrm{br}$ & 800 & 1511 & & 0.0 & 0.0 & 0 & 0.00 & - \\
\hline $439 b^{2)}$ & 800 & 1526 & & 1.4 & 2.1 & 856 & 0.22 & - \\
\hline $388 \mathrm{br}$ & 800 & 1527 & & 4.8 & 2.8 & 858 & 0.21 & viscous \\
\hline $445 b r$ & 800 & 1578 & sieved & 4.7 & 3.0 & 415 & 0.09 & viscous \\
\hline $419 b r$ & 800 & 1556 & hot pressed & 4.2 & 2.8 & 1159 & 0.25 & viscous \\
\hline $412 \mathrm{br}$ & 900 & 1530 & & 2.9 & 2.8 & 475 & 0.10 & viscous \\
\hline $417 \mathrm{br}$ & 1000 & 1576 & & 0.0 & 0.0 & 0 & 0.00 & - \\
\hline $337 \mathrm{br}$ & 1000 & 1506 & & 3.2 & 3.0 & 152 & 0.05 & viscous \\
\hline $494 \mathrm{br}$ & 650 & 1088 & & 5.7 & 4.8 & 2396 & 0.49 & transitional \\
\hline $452 \mathrm{br}$ & 700 & 1064 & & 4.4 & 2.7 & 1536 & 0.40 & transitional \\
\hline $448 b r$ & 800 & 1067 & & 4.5 & 2.9 & 864 & 0.25 & viscous \\
\hline $386 b r$ & 800 & 574 & & 3.2 & 2.3 & 1500 & 0.53 & brittle \\
\hline $500 \mathrm{br}$ & 650 & 1502 & & 1.1 & 0.3 & 1276 & 0.30 & - \\
\hline $447 \mathrm{br}$ & 800 & 1556 & & 4.1 & 27.0 & 1783 & 0.35 & transitional \\
\hline $499 \mathrm{br}$ & 900 & 1535 & & 4.0 & 189.0 & 2015 & 0.39 & transitional \\
\hline
\end{tabular}




\begin{tabular}{|c|c|c|c|c|c|c|c|}
\hline Sample & $\begin{array}{c}\text { Temperature } \\
\left({ }^{\circ} \mathrm{C}\right)\end{array}$ & $\begin{array}{c}\text { Confining } \\
\text { Pressure } \\
\text { (MPa) }\end{array}$ & Shear strain & $\begin{array}{c}\text { Stress } \\
\text { exponent }\end{array}$ & $\begin{array}{c}\text { Shear strain rate } \\
\qquad\left(\mathrm{s}^{-1}\right)\end{array}$ & Flow stress (MPa) & $\begin{array}{l}\text { Friction coefficient } \\
\qquad\left(\mu=\tau / \sigma_{n}\right)\end{array}$ \\
\hline $498 \mathrm{br}$ & $650^{1)}$ & 1589 & 5.4 & 6.4 & $\begin{array}{l}2.60 \\
1.20 \\
0.30\end{array}$ & $\begin{array}{r}2608 \\
2517 \\
1842\end{array}$ & $\begin{array}{l}0.46 \\
0.44 \\
0.36\end{array}$ \\
\hline $488 \mathrm{br}$ & 800 & 1623 & 6.4 & 1.8 & $\begin{array}{c}28.00 \\
5.10 \\
1.20 \\
0.48^{2)}\end{array}$ & $\begin{array}{r}1811 \\
783 \\
422 \\
250\end{array}$ & $\begin{array}{l}0.37 \\
0.20 \\
0.11 \\
0.07\end{array}$ \\
\hline $480 \mathrm{br}^{3)}$ & 800 & 1601 & 4.5 & & $\begin{array}{l}2.30 \\
0.63 \\
2.70\end{array}$ & $\begin{array}{l}1040 \\
293 \\
820\end{array}$ & $\begin{array}{l}0.25 \\
0.09 \\
0.20\end{array}$ \\
\hline $482 \mathrm{br}$ & 900 & 1583 & 8.4 & 2.0 & $\begin{array}{c}28.00 \\
3.60 \\
0.49 \\
41.00^{4)}\end{array}$ & $\begin{array}{c}1272 \\
389 \\
178 \\
1494\end{array}$ & $\begin{array}{l}0.29 \\
0.11 \\
0.05 \\
0.32\end{array}$ \\
\hline $485 \mathrm{br}$ & 1000 & 1588 & 6.2 & & $\begin{array}{c}27.00 \\
4.00 \\
0.37 \\
34.00\end{array}$ & $\begin{array}{c}578 \\
189 \\
75 \\
794\end{array}$ & $\begin{array}{l}0.16 \\
0.06 \\
0.02 \\
0.20\end{array}$ \\
\hline
\end{tabular}




\begin{tabular}{|c|c|c|c|c|c|c|c|c|c|c|c|c|}
\hline Sample & $\begin{array}{c}\mathrm{T} \\
{\left[{ }^{\circ} \mathrm{C}\right]}\end{array}$ & $\begin{array}{c}\mathrm{Pc} \\
{[\mathrm{GPa}]}\end{array}$ & $\begin{array}{c}\dot{\gamma} \\
{\left[10^{-5} \cdot \mathrm{s}^{-1}\right]}\end{array}$ & $\begin{array}{l}\text { Width } \\
{[\mathrm{px}]}\end{array}$ & $\begin{array}{c}\text { Height } \\
{[\mathrm{px}]}\end{array}$ & $\begin{array}{c}\text { Step size } \\
{[\mu \mathrm{m}]}\end{array}$ & $\begin{array}{l}\text { No. of } \\
\text { grains }\end{array}$ & $\begin{array}{c}\text { 2D mean }{ }^{1)} \\
{[\mu \mathrm{m}]}\end{array}$ & $\begin{array}{l}\left.\text { 2D median }{ }^{2}\right) \\
{[\mu \mathrm{m}]}\end{array}$ & $\begin{array}{c}\text { 2D RMS }{ }^{3)} \\
{[\mu \mathrm{m}]}\end{array}$ & $\begin{array}{c}\text { 3D mode }{ }^{4)} \\
{[\mu \mathrm{m}]}\end{array}$ & $\begin{array}{c}\left.\text { 3D st.dev. }{ }^{5}\right) \\
{[\mu \mathrm{m}]}\end{array}$ \\
\hline $487 b^{6)}$ & $800^{\circ}$ & 1.5 & - & 700 & 625 & 0.20 & 386 & 5.21 & 4.31 & 6.50 & 9.1 & 2.7 \\
\hline $417 b r^{7)}$ & $1000^{\circ}$ & 1.5 & - & 1250 & 1649 & 0.20 & 583 & 7.56 & 6.65 & 9.21 & 12.8 & 4.3 \\
\hline $383 \mathrm{br}$ & 700 & 1.5 & 2.8 & 525 & 325 & 0.20 & 3988 & 0.98 & 0.75 & 1.41 & 2.1 & 0.5 \\
\hline $388 \mathrm{br}$ & 800 & 1.5 & 2.8 & 500 & 500 & 0.20 & 1517 & 2.27 & 1.86 & 2.90 & 4.1 & 1.9 \\
\hline $412 \mathrm{br}$ & 900 & 1.5 & 2.8 & 925 & 850 & 0.20 & 2789 & 3.02 & 2.67 & 3.79 & 6.1 & 0.9 \\
\hline $337 \mathrm{br}$ & 1000 & 1.5 & 3 & 1250 & 1000 & 0.20 & 696 & 5.80 & 4.53 & 7.99 & 15.3 & 13.4 \\
\hline $493 b^{8}{ }^{8}$ & 700 & 1.5 & 2.7 & 400 & 350 & 0.20 & 3518 & 0.93 & 0.77 & 1.36 & 1.6 & 0.2 \\
\hline $419 b^{8)}$ & 800 & 1.5 & 2.8 & 800 & 900 & 0.15 & 2257 & 2.34 & 1.99 & 3.00 & 4.8 & 0.8 \\
\hline $445 b r^{9)}$ & 800 & 1.5 & 3 & 1200 & 700 & 0.10 & 2495 & 1.30 & 0.78 & 2.05 & 4.4 & 3.7 \\
\hline $452 \mathrm{br}$ & 700 & 1 & 2.7 & 820 & 600 & 0.15 & 9716 & 0.77 & 0.63 & 1.12 & 1.5 & 0.2 \\
\hline $448 \mathrm{br}$ & 800 & 1 & 2.9 & 1600 & 900 & 0.10 & 4102 & 1.49 & 1.17 & 2.1 & 3.3 & 0.5 \\
\hline $447 \mathrm{br}$ & 800 & 1.5 & 27 & 1000 & 750 & 0.20 & 16390 & 1.173 & 1.01 & 1.51 & 2.0 & 0.3 \\
\hline $499 \mathrm{br}$ & 900 & 1.5 & 189 & 708 & 512 & 0.20 & 11521 & 0.914 & 0.81 & 1.22 & 1.5 & 0.2 \\
\hline
\end{tabular}




\begin{tabular}{|c|c|c|c|c|c|c|}
\hline Source & $\begin{array}{l}\text { Confining } \\
\text { pressure } \\
\text { Pc [GPa] }\end{array}$ & $\begin{array}{c}\text { Stress } \\
\text { exponent } \\
n\end{array}$ & $\begin{array}{c}\text { Activation } \\
\text { energy Q } \\
{[\mathrm{kJ} / \mathrm{mol}]}\end{array}$ & $\begin{array}{c}\text { Factor A } \\
{[\mathrm{MPa}-1 \mathrm{~s}-1]}\end{array}$ & Material & Water content \\
\hline Jaoul et al. (1984) & 1.5 & $1.4-2.4$ & $146-172$ & $\begin{array}{l}2.95 \cdot 10^{-4} \text { to } \\
7.68 \cdot 10^{-8}\end{array}$ & $\begin{array}{c}\text { Heavitree Quartzite } \\
\mathrm{d}=0.2 \mathrm{~mm}\end{array}$ & $\mathrm{H}_{2} \mathrm{O}$ in different amounts \\
\hline Kronenberg \& Tullis (1984) & $0.9-1.45$ & $2.9-3.2$ & $170-220$ & - & $\begin{array}{l}\text { Heavitree Quartzite } \\
\qquad \mathrm{d}=211 \mu \mathrm{m}\end{array}$ & As-is \\
\hline Kronenberg \& Tullis (1984) & 1.5 & 2.5 & $120-150$ & - & $\begin{array}{l}\text { Novaculite } \\
\mathrm{d}=4.9 \mu \mathrm{m}\end{array}$ & $0.4 \mathrm{wt} \% \mathrm{H}_{2} \mathrm{O}$ added \\
\hline Paterson \& Luan (1990) & 0.3 & 2.3 & 150 & - & $\begin{array}{c}\text { Silica Gel } \\
\mathrm{d}=30-80 \mu \mathrm{m}\end{array}$ & $1000-10000 \mathrm{H} / 106 \mathrm{Si}$ \\
\hline Paterson \& Luan (1990) & 0.3 & 3.9 & 150 & $\sim 4.0 \cdot 10^{-10}$ & $\begin{array}{c}\text { Silicic Acid } \\
\mathrm{d}=20 \mu \mathrm{m}\end{array}$ & $1000-10000 \mathrm{H} / 106 \mathrm{Si}$ \\
\hline Gleason \& Tullis (1995) & $1.5-1.7$ & $3.9-4.1$ & $137-223$ & $1.1 \cdot 10^{-4}$ & $\begin{array}{c}\text { Black Hills Quartzite } \\
\mathrm{d}=100 \mu \mathrm{m}\end{array}$ & $0.15 \mathrm{wt} \% \mathrm{H}_{2} \mathrm{O}$ added \\
\hline Hirth et al. (2001) & - & 4 & 135 & $6.3 \cdot 10^{-12}$ & $\begin{array}{c}\text { Fitted flow law } \\
\text { experimental / natural }\end{array}$ & - \\
\hline Rutter \& Brodie (2004a) & 0.3 & 2.97 & 224 & $1.17 \cdot 10^{-5}$ & $\begin{array}{c}\text { Synthetic } \\
\mathrm{d}=12-20 \mu \mathrm{m}\end{array}$ & $0.6 \mathrm{wt} \%$ \\
\hline Rutter \& Brodie (2004b) & 0.3 & 1 & 220 & 0.4 & $\begin{array}{c}\text { Synthetic } \\
\mathrm{d}=0.4,1.3,4.5 \mu \mathrm{m}\end{array}$ & $0.6 \mathrm{wt} \%$ \\
\hline This Study & 1.5 & $1.8-2.0$ & $168-170$ & $3.1 \cdot 10^{-4}$ & $\begin{array}{l}\text { Crushed Quartz } \\
\mathrm{d}<100 \mu \mathrm{m}\end{array}$ & $0.2 \mathrm{wt} \% \mathrm{H}_{2} \mathrm{O}$ added \\
\hline
\end{tabular}


(a)

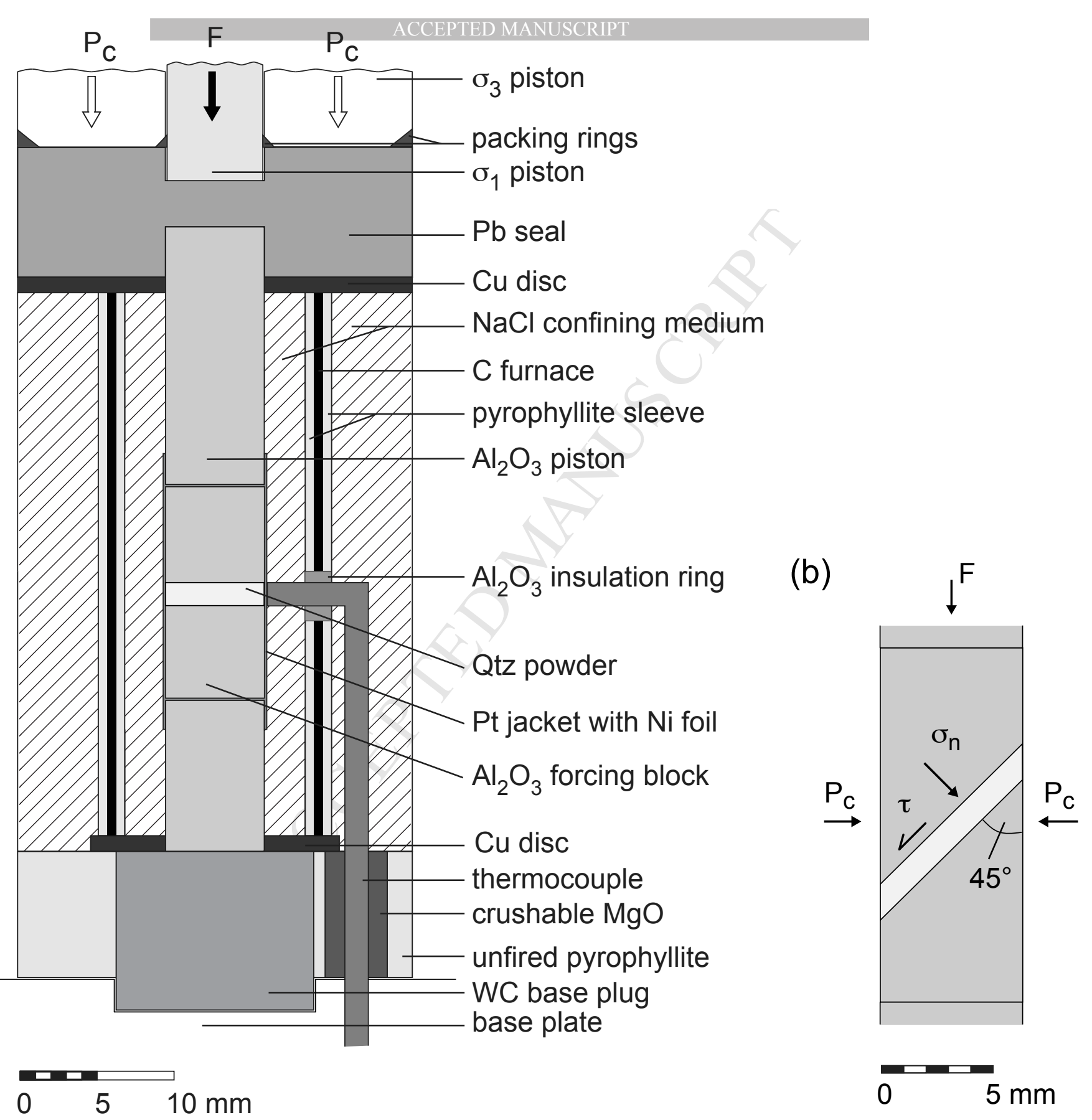



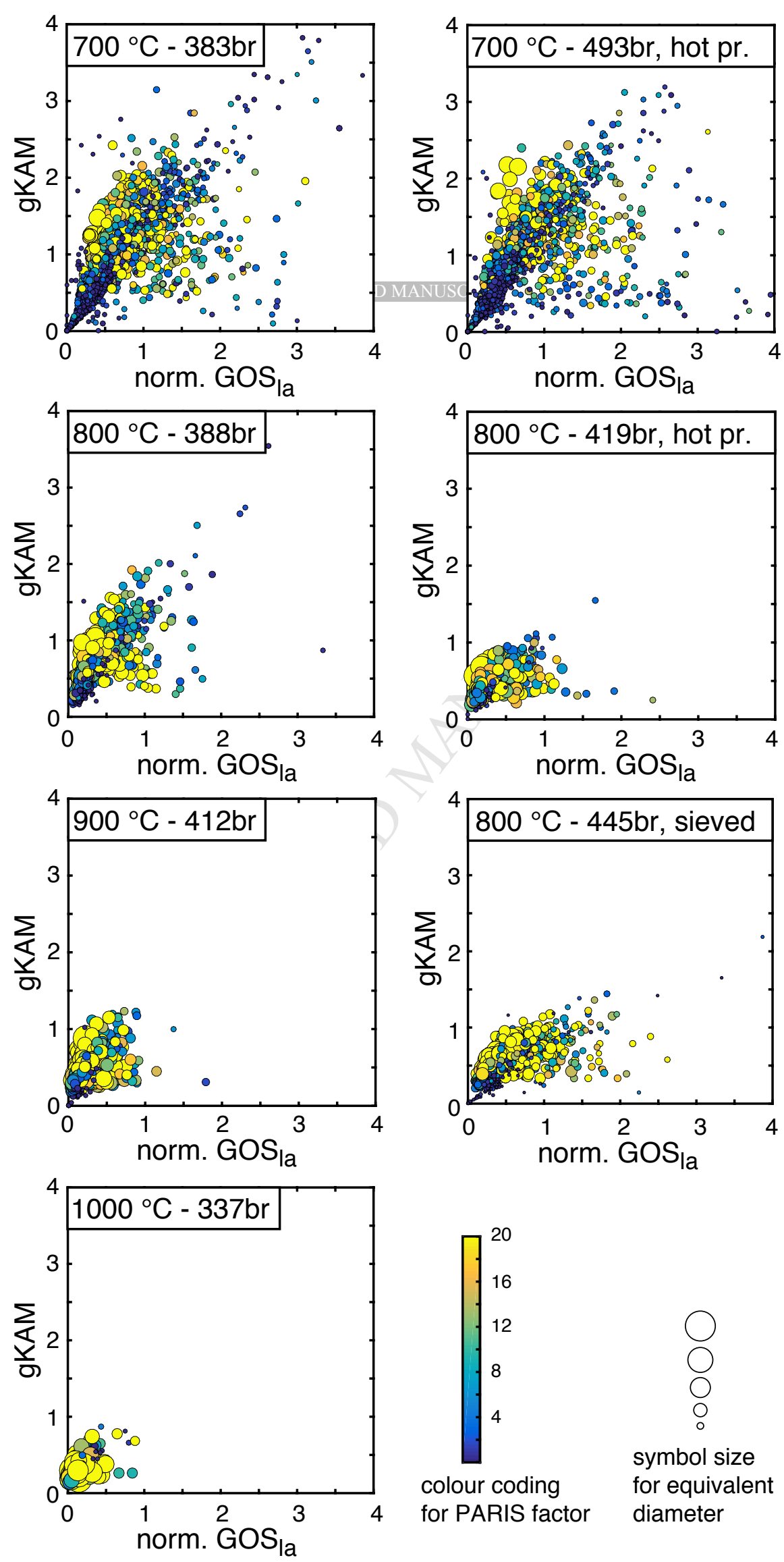

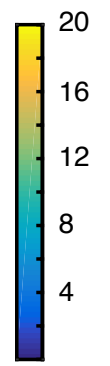

colour coding for PARIS factor symbol size for equivalent diameter 
- $-\mu$ at $\gamma=3$ $\mu$ from strain
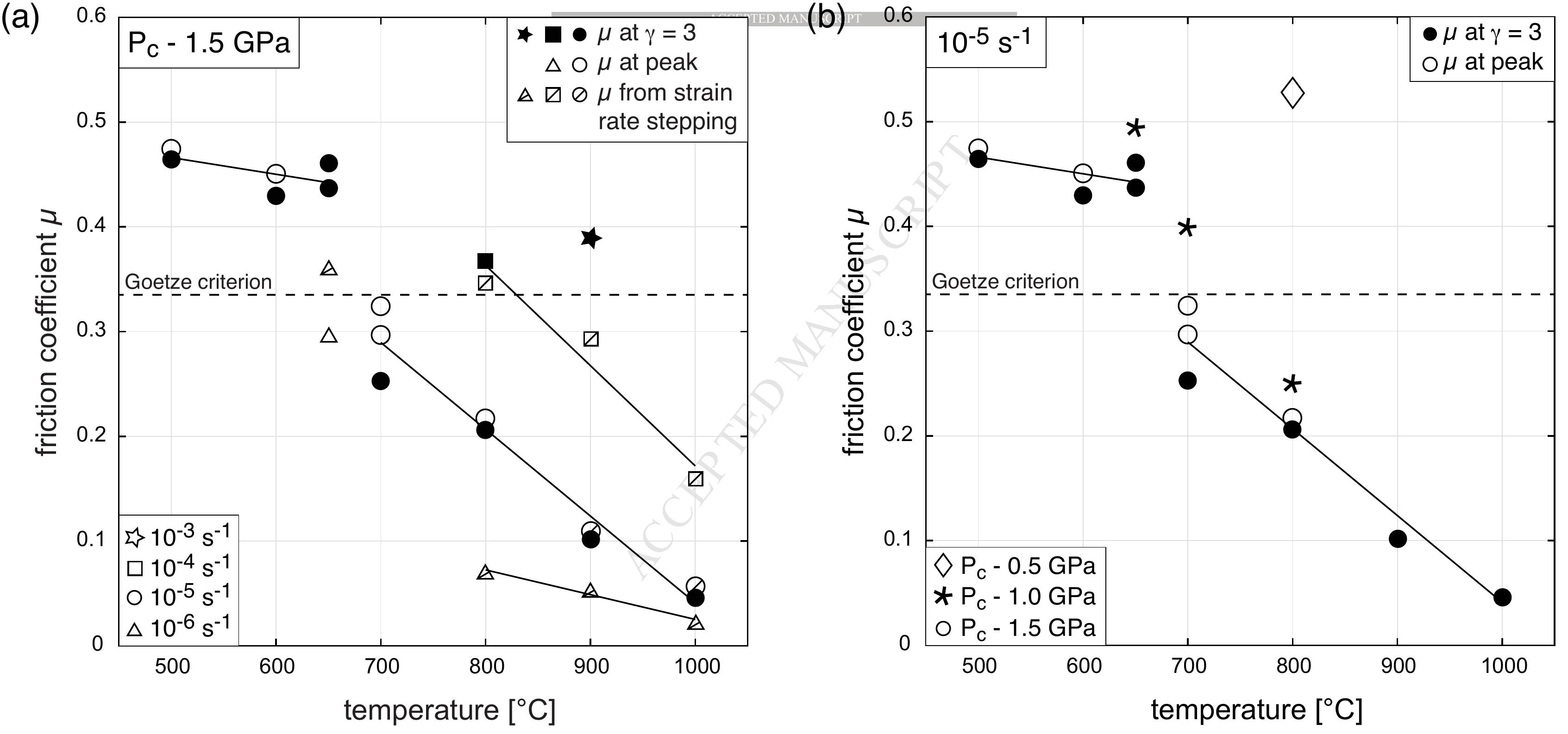
(b)
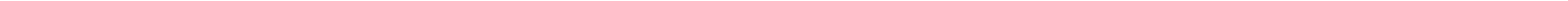

(c)

(a)
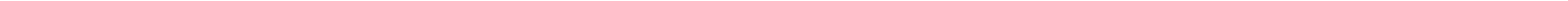

(
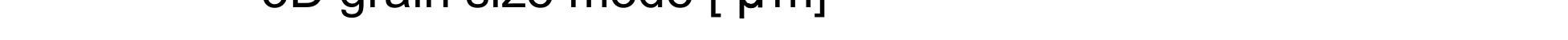
(a)

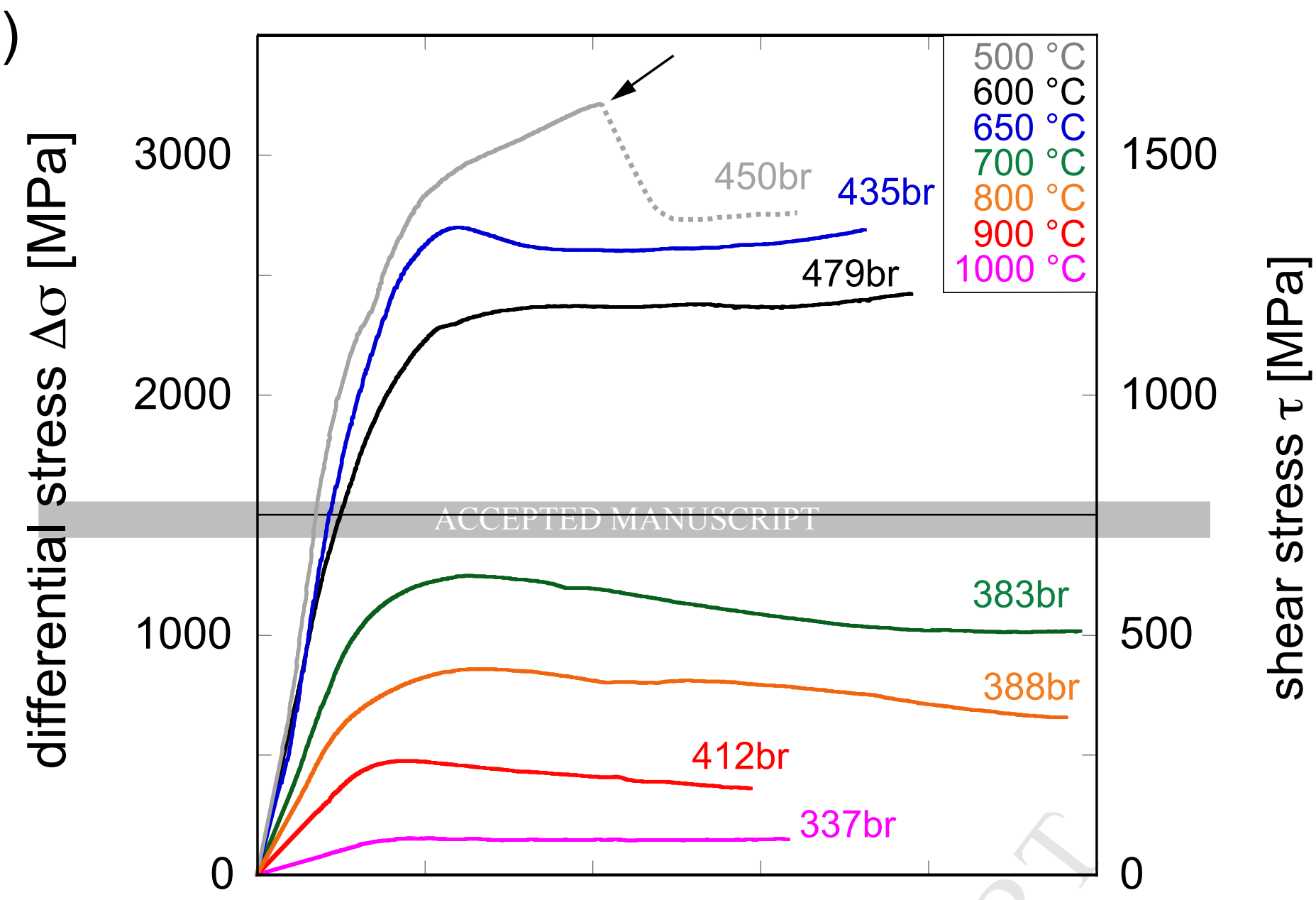

(b)

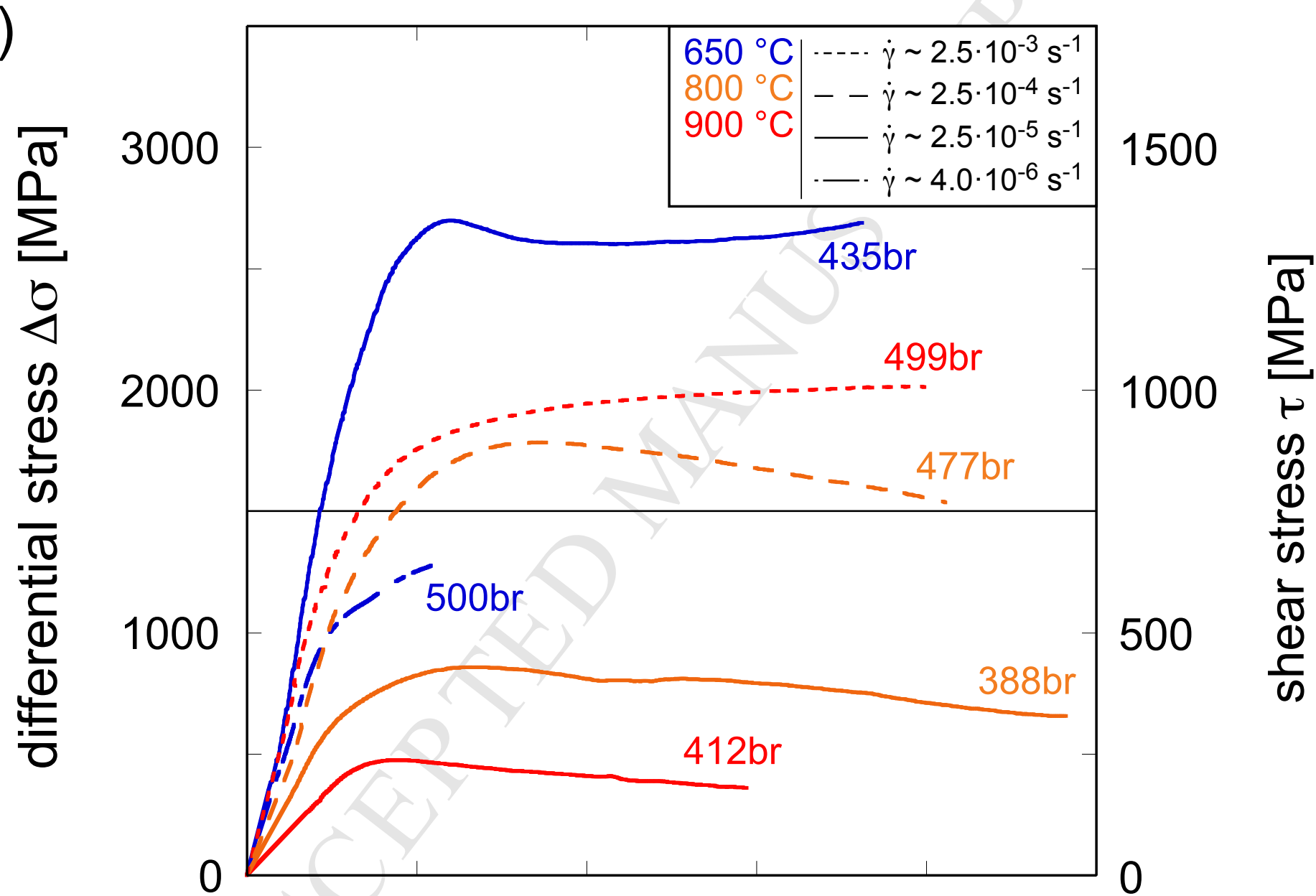

(c)

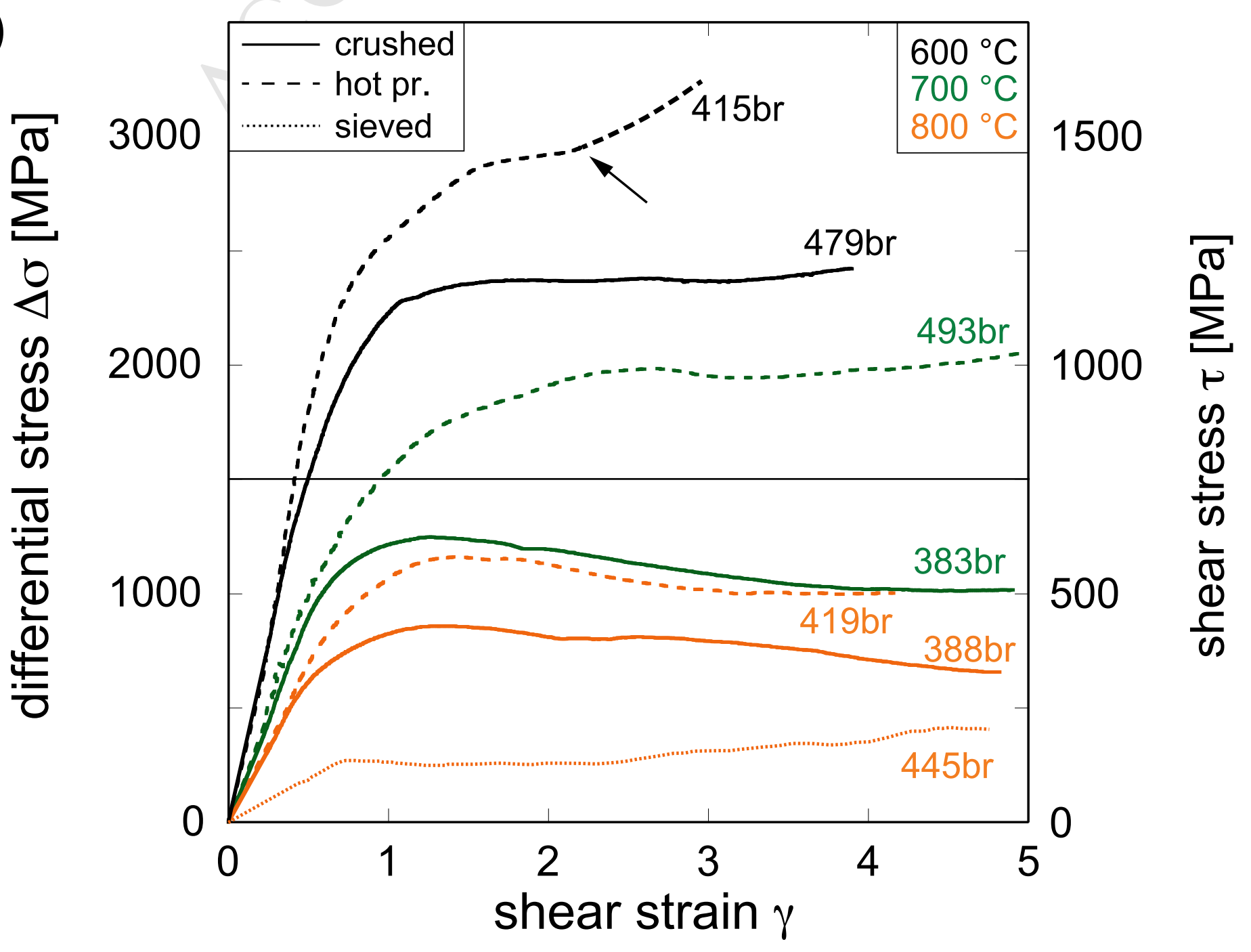



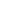


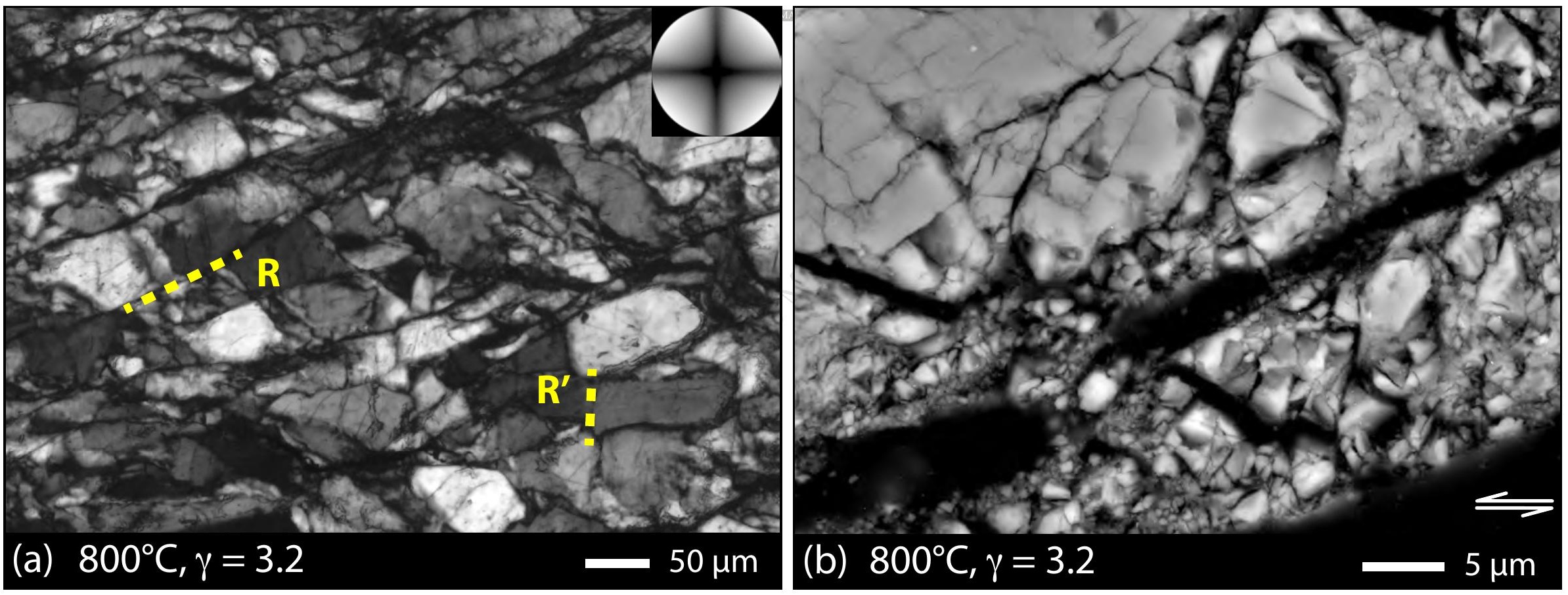


Highlights:

(1) New large data set defines brittle to viscous transition in quartz

(2) Low stress exponent of $n=1.9+0.6$ between $800 \mathrm{C}$ and $1000 \mathrm{C}$ for viscous deformation

(3) Viscous deformation by combination of dislocation and diffusion (solution precipitation) creep

(4) Simultaneous diffusion and dislocation creep partition into different grain sizes, shown by CPO

(5) Goetze criterion is confirmed as upper stress limit of viscous deformation 